\title{
Impact of Mass-Size Parameterizations of Frozen Hydrometeors on Microphysical Retrievals: Evaluation by Matching Radar to In Situ Observations from GCPEX and OLYMPEx
}

\author{
Ousmane O. Sy, ${ }^{\mathrm{a}}$ Simone Tanelli, ${ }^{\mathrm{a}}$ StePhen L. Durden, ${ }^{\mathrm{a}}$ Andrew Heymsfield, ${ }^{\mathrm{b}}$ \\ AARON BANSEMER, ${ }^{\mathrm{b}}$ KWO-SEN KUO,${ }^{\mathrm{c}}$ NOPPASIN NiAMSUWAN, ${ }^{\mathrm{a}}$ ROBERT M. BEAUCHAMP, ${ }^{\mathrm{a}}$ \\ V. CHANDRASEKAR, ${ }^{\mathrm{d}}$ MANUEl VEGA, ${ }^{\mathrm{c}}$ AND MiCHAEL P. JOHNSON ${ }^{\mathrm{a}}$

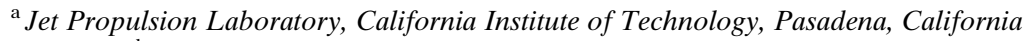 \\ ${ }^{\mathrm{b}}$ National Center for Atmospheric Research, Boulder, Colorado \\ ${ }^{\mathrm{c}}$ NASA Goddard Space Flight Center, Greenbelt, Maryland \\ ${ }^{\mathrm{d}}$ Colorado State University, Fort Collins, Colorado
}

(Manuscript received 20 June 2019, in final form 1 April 2020)

\begin{abstract}
This article illustrates how multifrequency radar observations can refine the mass-size parameterization of frozen hydrometeors in scattering models and improve the correlation between the radar observations and in situ measurements of microphysical properties of ice and snow. The data presented in this article were collected during the GPM Cold Season Precipitation Experiment (GCPEx) (2012) and Olympic Mountain Experiment (OLYMPEx) (2015) field campaigns, where the true mass-size relationship was not measured. Starting from size and shape distributions of ice particles measured in situ, scattering models are used to simulate an ensemble of reflectivity factors for various assumed mass-size parameterizations (MSP) of the power-law type. This ensemble is then collocated to airborne and ground-based radar observations, and the MSPs are refined by retaining only those that reproduce the radar observations to a prescribed level of accuracy. A versatile "retrieval dashboard" is built to jointly analyze the optimal MSPs and associated retrievals. The analysis shows that the optimality of an MSP depends on the physical assumptions made in the scattering simulators. This work confirms also the existence of a relationship between parameters of the optimal MSPs. Through the MSP optimization, the retrievals of ice water content $M$ and mean diameter $D_{m}$ seem robust to the change in meteorological regime (between GCPEx and OLYMPEx); whereas the retrieval of the diameter spread $S_{m}$ seems more campaign dependent.
\end{abstract}

\section{Introduction}

Numerical weather models must account for the spatial distribution of snow and ice in the atmosphere, given their importance in the hydrological and energy cycles of Earth (Stephens et al. 2012). Spaceborne profiling radars are well suited for measuring the spatial distribution of frozen precipitation globally. The current fleet of spaceborne radars consists of the W-band cloud profiling radar of CloudSat (Stephens et al. 2008), the Dual-Frequency (Ku, Ka) Precipitation Radar (DPR) of the Global Precipitation Measurement (GPM) Core Observatory (Hou et al. 2014) and the Ka-band radar in a CubeSat (RainCube) of the Jet Propulsion Laboratory (JPL) (Peral et al. 2019). Radar measurements result from the contributions of all

Corresponding author: Ousmane O. Sy, ousmane.o.sy@jpl.nasa.gov the particles of water (in their liquid, solid. or mixedphase form) contained in the resolution volume (RV; with typical dimensions of a few kilometers horizontally and $\sim 250 \mathrm{~m}$ vertically). The content of the RV is characterized statistically through the particle size distribution (PSD), which describes the number of particles of a given maximum dimension $D$ per unit volume, and the mass-size parameterization (MSP), which defines the mass of particles of size $D$. Radar reflectivities can be regarded as statistical moments of the PSD weighted by the backscattering cross sections of particles. The radar cross section of a hydrometeor is frequency dependent and strongly correlated to the particle's mass, shape, and phase. In this paper we focus on conditions where the hydrometeors are prevalent in their solid state, and as "low-density" habits (i.e., not mixed phases from the melting layer of precipitation, hail, nor high-density graupel). 
With frozen particles, characterizing the MSP or PSD via radar reflectivity measurements is challenging for multiple reasons. The morphological diversity of frozen particles induces a large variability of their masses and electromagnetic properties. Mathematically, it is difficult to disentangle the effect of the PSD from that of the MSP on the radar reflectivity. Moreover, characterizing MSP and PSD by a few scalars (radar observations) is impossible unless one parameterizes the spectra (e.g., gamma models for the PSD, power laws for the MSP) or focuses on mass-weighted bulk moments of the PSD.

Here, we examine specifically the potential of a multifrequency radar approach that spans the frequencies traditionally employed in spaceborne cloud and precipitation radars. Efforts to quantify the uncertainties associated with radar retrievals of ice microphysics are affected by a number of challenges: the scarcity of viable datasets, their delicate quality control and collocation, interpretation of measurement errors, and the interplay between particle mass and shape, which affect the scattering properties at various wavelengths. "Ideal" retrieval conditions are usually met only in fully controlled numerical experiments, or in field campaigns where remote sensing and in situ sampling instruments are operated jointly. Even in such contexts, errors are introduced by the mathematical approximations made to construct retrieval operators.

The aim of this article is to use dual-frequency radar observations $(\mathrm{Ku}, \mathrm{Ka})$ to refine the mass-size parameterization of frozen hydrometeors in scattering models and, thereby, improve the correlation between radar observables and retrievals of microphysical properties of snow. To this end, we use data from two field campaigns, namely, the GPM Cold Season Precipitation Experiment (GCPEx; Ontario, Canada, 2012) (Skofronick-Jackson et al. 2015), and the Olympic Mountain Experiment (OLYMPEx; state of Washington, 2015) (Houze et al. 2017). In both campaigns, remote sensing instruments and in situ probes were deployed jointly. Of particular interest to this study are 1) the instruments on the Citation aircraft (CIT) of the University of North Dakota, which measured in situ thermodynamics and particle images from which PSDs were derived, and 2) the radar measurements acquired by JPL's Airborne Precipitation Radar (APR) (Sadowy et al. 2003; Durden et al. 2020) and the ground-based dual-frequency dual-polarized Doppler radar (D3R) (Vega et al. 2014).

The in situ data provide a reference for the "true" state of the atmosphere and the PSD. However, none of the instruments measured the mass-size spectrum of particles, thus leaving the MSP uncertain. To quantify this uncertainty, we start from the measured PSDs and assume various MSPs to simulate unattenuated radar reflectivities at all bands of interest. Next, collocated radar observations are used to constrain the scattering simulations. The objective of this " $Z$ constrained" optimization is twofold: 1) to evaluate how well the MSP-perturbed simulations approximate the collocated observations, and 2) to study the sensitivity of the bulk moments associated with the optimal MSPs, which we consider as our retrievals (ice water content $M$, mean mass-weighted diameter $D_{m}$, and spread $S_{m}$ ).

A number of case studies using data from specific events in GCPEx and OLYMPEx have been completed (Heymsfield et al. 2018; Huang et al. 2019; Leinonen et al. 2018; Chase et al. 2018; Durden et al. 2020). In this paper, we use all the in situ, APR and D3R data from GCPEx and OLYMPEx. Fontaine et al. (2014), Wood et al. (2015), Falconi et al. (2018), and Finlon et al. (2019) have conducted analyses similar to ours using data from Cirrus Regional Study of Tropical Anvils and Cirrus Layers-Florida-Area Cirrus Experiment (CRYSTAL-FACE), Canadian CloudSat/CALIPSO Validation Programme (C3VP), Biogenic Aerosols Effects on Clouds and Climate (BAECC), and Midlatitude Continental Convective Clouds Experiment (MC3E), respectively. The meteorological regimes sampled during GCPEx and OLYMPEx were quite different from those sampled during CRYSTAL-FACE, C3VP, BAECC and MC3E. A "retrieval dashboard" will be used to jointly analyze the optimal MSPs and associated retrievals in a radar and thermodynamic context.

The outline of this article is as follows. Section 2 gives an overview of the instruments deployed during GCPEx and OLYMPEx and describes the strategy to collocate the various datasets. In section 3, the scattering calculations are outlined by assuming a fixed mass-size relationship. Then, we present the bank of parameterizations for evaluation. Section 4 describes the MSP optimization, discusses our choice of references for retrieved moments, and, presents the retrieval dashboard used to analyze the optimal MSPs. Section 5 compares retrievals from GCPEx to those from OLYMPEx. Last, in section 6 we study the sensitivity of the retrievals of $M, D_{m}$, and $S_{m}$ to the quantization of the space of MSPs and the scattering models.

\section{Overview of datasets and collocation strategy}

\section{a. Datasets}

GCPEx took place in Ontario, Canada, between January and March 2012, and was led by NASA and Environment Canada (EC). As shown in Table 1, the meteorological events sampled consisted mostly of light precipitation in the form of snowfall (Skofronick-Jackson et al. 2015). 
TABLE 1. Meteorological events during GCPEx and OLYMPEx and number of radar observations with collocated CIT (at all temperatures) for collocation margins $\left(\delta_{r}=0.5 \mathrm{~km}, \delta_{h}=50 \mathrm{~m}, \delta_{t}=5 \mathrm{~min}\right)$.

\begin{tabular}{|c|c|c|c|c|c|c|c|}
\hline \multicolumn{4}{|c|}{ GCPEx } & \multicolumn{4}{|c|}{ OLYMPEx } \\
\hline \multirow[b]{2}{*}{ Date } & \multirow[b]{2}{*}{ Meteorological event } & \multicolumn{2}{|c|}{$\begin{array}{l}\text { Number of } \\
\text { records }\end{array}$} & \multirow[b]{2}{*}{ Date } & \multirow[b]{2}{*}{ Meteorological event } & \multicolumn{2}{|c|}{$\begin{array}{c}\text { Number of } \\
\text { records }\end{array}$} \\
\hline & & APR & D3R & & & APR & D3R \\
\hline 19 Jan 2012 & Light snowfall & 8408 & 8890 & 12 Nov 2015 & Pre-/cold-frontal rain & 9811 & 7539 \\
\hline 27 Jan 2012 & Cold/freezing rain & 29230 & 15230 & 13 Nov 2015 & Pre-/cold-frontal rain & 6789 & 2484 \\
\hline 28 Jan 2012 & Light snowfall/lake effect & 19973 & 12283 & 14 Nov 2015 & Pre-/cold-frontal rain & - & 5059 \\
\hline 30 Jan 2012 & Moderate snowfall & 528 & 4811 & 18 Nov 2015 & Shallow postfrontal convection & 908 & 856 \\
\hline 31 Jan 2012 & Moderate snowfall & 8182 & - & 23 Nov 2015 & Collapsing frontal system & 1514 & - \\
\hline 12 Feb 2012 & Lake effect & 6678 & 1333 & 24 Nov 2015 & Collapsing frontal system & 509 & - \\
\hline 13 Feb 2012 & & 8116 & - & 1 Dec 2015 & Stratiform/orographics & 4528 & 1577 \\
\hline 14 Feb 2012 & Light snowfall & - & 7278 & 2 Dec 2015 & Stratiform/orographics & 3248 & - \\
\hline 18 Feb 2012 & Heavy snow & - & 26755 & 3 Dec 2015 & Baroclinic system/orographics & 4446 & 1731 \\
\hline \multirow[t]{7}{*}{24 Feb 2012} & Light snowfall/lake effect & 17877 & 3545 & 4 Dec 2015 & Postfrontal convection & 2838 & 1882 \\
\hline & & & & 5 Dec 2015 & Large frontal system & 6480 & 10964 \\
\hline & & & & 10 Dec 2015 & Postfrontal convection & 2079 & - \\
\hline & & & & 12 Dec 2015 & Occluded front & 5129 & 13251 \\
\hline & & & & 13 Dec 2015 & Postfrontal convection & 2433 & 430 \\
\hline & & & & 18 Dec 2015 & Weak/mixed frontal & - & 4619 \\
\hline & & & & 19 Dec 2015 & Weak postfrontal convection & 988 & 105 \\
\hline \multicolumn{2}{|c|}{ Total number of collocated records } & 98985 & 80118 & \multicolumn{2}{|c|}{ Total number of collocated records } & 51687 & 50486 \\
\hline
\end{tabular}

OLYMPEx, led by NASA with significant contributions from EC, took place in Washington State, between November 2015 and February 2016. OLYMPEx sampled a variety of heavy precipitation ranging from stratiform to convective systems (see Table 1) (Houze et al. 2017).

GCPEx and OLYMPEx were ground-validation experiments to improve the snowfall retrieval algorithms of GPM. In both experiments, the CIT measured the state of the atmosphere using sensors for temperature, King and Nevzorov probes for the water content, and High Volume Precipitation Spectrometer, version 3 (HVPS3), and two-dimensional stereo (2DS) particle imaging probes. The particle images were processed to derive PSD and aspect ratio spectra, for $D \in[0.8,30] \mathrm{mm}$ $(D \in[0.1,1.28] \mathrm{mm})$ for HVPS3 (2DS) (SkofronickJackson et al. 2015). The 2DS and HVPS3 observations were combined at $1 \mathrm{~mm}$ to produce a PSD for $D \in$ $[0.1,30] \mathrm{mm}$. The significant quality control of the image processing included corrections for shattered particles, removal of coincident particles in the same frame, and rejection of particles due to poor focus or instrument malfunction (Heymsfield and Parrish 1978; Field et al. 2006; McFarquhar et al. 2017).

Radar observations were acquired by APR flown on NASA's DC8 aircraft, and by the ground-based D3R. During GCPEx, APR was in its "second generation" (APR2) version and recorded Ku- and Ka-band data. OLYMPEx marked the first deployment of APR3 (third generation), with observations at $\mathrm{Ku}, \mathrm{Ka}$, and $\mathrm{W}$ bands
(Durden et al. 2020). This article will focus on $\mathrm{Ku}$ - and Ka-band reflectivities, since these channels are common to GCPEx and OLYMPEx and to APR and D3R, respectively. Some results of W-band measurements (only available from APR in OLYMPEx) will be shown but only for illustration purposes. APR is a cross-track scanning $\left( \pm 25^{\circ}\right)$ radar with a 30-m range sampling (Sadowy et al. 2003). D3R (Ku- and Ka-band radar), with a range sampling of $150 \mathrm{~m}$ and maximum range of $30 \mathrm{~km}$, was operated from the Centre for Atmospheric Research Experiments (CARE) site (in Barrie, Ontario) during GCPEx, and from the NPOL site (near Taholah, Washington) during OLYMPEx. Owing to the spatial resolution and sensitivity of APR (detection thresholds of $\sim(0,-20,-30) \mathrm{dB} Z$, at $10-\mathrm{km}$ distance for $\mathrm{Ku}, \mathrm{Ka}$, and $\mathrm{W}$ bands), it can detect fine atmospheric features that can be challenging to detect by D3R (thresholds at $\sim(-15,5) \mathrm{dBZ}$ at $10-\mathrm{km}$ range for $\mathrm{Ku}$ and $\mathrm{Ka}$ bands in GCPEx, and $\sim(-10,5) \mathrm{dB} Z$ in OLYMPEx $)$, especially when D3R is pointed at a high elevation angle.

APR and D3R records have been calibrated independently. For APR, the absolute calibration of the $\mathrm{Ku}$ band was done using surface returns from clear-air profiles over water bodies (Great Lakes in GCPEx, Pacific Ocean in OLYMPEx); Ka and W bands were calibrated relative to Ku band by ensuring the consistency between 1) surface returns over water and 2) echoes from cloud tops where all channels should be in Rayleigh scattering regime (Durden et al. 2020). For D3R, the reflectivity was calibrated "absolutely" using a metal 
sphere and a tower-mounted corner reflector. For the relative calibration, the reflectivity estimates were verified for consistency using light-rain measurements close to the radar (Vega et al. 2014). Both for APR and D3R, calibration absolute errors are within $1 \mathrm{~dB}$.

Given the observing geometries of APR (top-down) and D3R (bottom-up), attenuation affects the observed precipitation in different ways. We correct for gaseous attenuation using a standard millimeter-wave propagation model (Liebe 1985). The required profiles of temperature, pressure and relative humidity are obtained from MERRA (Rienecker et al. 2011). We do not attempt to correct for attenuation by condensed water to avoid introducing errors that could bias our analyses. Instead, we screen the profiles where the attenuation due to liquid or mixed-phase particles is severe and use only profiles where the path attenuations at $\mathrm{Ku}$ and $\mathrm{Ka}$ bands are negligible (see details in section $4 \mathrm{a}$ and appendix A).

\section{b. Collocation strategy}

We adopt a radar-centric approach to collocate in situ measurements with radar observations. This allows us to identify all in situ samples that are relevant to each radar observation, and establishes an invariant mapping of the in situ data on the radar data, so that there is no need to recollocate in situ data after each reprocessing of the radar data. To clarify the description, let $P_{\mathrm{RAD}}\left(t_{\mathrm{RAD}}\right)=$ $\left[r_{\mathrm{RAD}}\left(t_{\mathrm{RAD}}\right), h_{\mathrm{RAD}}\left(t_{\mathrm{RAD}}\right)\right]$ be the spatial coordinates of a valid radar record (APR or D3R) at time $t_{\mathrm{RAD}}$, with $r_{\mathrm{RAD}}\left(t_{\mathrm{RAD}}\right) \in \mathbb{R}^{2}$ the vector of local horizontal coordinates and $h_{\mathrm{RAD}}\left(t_{\mathrm{RAD}}\right)$ the altitude. Similarly, let $P_{\text {CIT }}\left(t_{\text {CIT }}\right)=\left[r_{\text {CIT }}\left(t_{\text {CIT }}\right), h_{\text {CIT }}\left(t_{\text {CIT }}\right)\right]$ be the coordinates of the CIT aircraft at time $t_{\mathrm{CIT}}$. We adopt collocation margins $\left(\delta_{r}=0.5 \mathrm{~km}, \delta_{h}=50 \mathrm{~m}, \delta_{t}=5 \mathrm{~min}\right)$ derived by an analysis of the spatiotemporal decorrelation of the radar signal. For every $P_{\mathrm{RAD}}\left(t_{\mathrm{RAD}}\right)$, we find all the $P_{\mathrm{CIT}}$ such that $\left|r_{\mathrm{CIT}}-r_{\mathrm{RAD}}\right| \leq \delta_{r},\left|h_{\mathrm{CIT}}-h_{\mathrm{RAD}}\right| \leq \delta_{h}$ and $\left|t_{\mathrm{CIT}}-t_{\mathrm{RAD}}\right| \leq \delta_{t}$ : these constitute the "close" CIT points. The data at the close points are uniformly averaged, which mitigates the impact of extreme values.

While the chosen collocation margins are tight, to warrant the simultaneity of the measurements from the various instruments, we still obtain large datasets, as shown by Table 1: more than 90000 (50000) airborne records and more than 80000 (50000) ground-based records for GCPEx (OLYMPEx). In what follows, we will replace the "RAD" subscript with " $A$ " and " $D$ " to specify APR and D3R data, respectively. Even though all the quantities (reflectivity factor, PSD) used in our article are normalized by the sampled volume, the volume sampled by the CIT is necessarily different (and smaller) than the RV of the radar. This could cause issues in terms of spatiotemporal representativeness. One way to mitigate this issue is to integrate in time the CIT measurements to increase the volume sampled by the in situ probes and obtain measurements that are more representative of the content of the RV. Here, the CIT data, initially sampled every second, are integrated over $5 \mathrm{~s}$ (which represents a sampled length between 600 and $1000 \mathrm{~m}$ for typical aircraft speeds).

Figure 1 shows the radar profiles of all cases of triple collocation APR-CIT-D3R in OLYMPEx. To find these profiles, we first consider the coordinates of the CIT-APR and CIT-D3R collocated samples, and require that the distance between CIT locations be within the $\left(\delta_{r}, \delta_{t}, \delta_{h}\right)$ margin. The resulting 435 profiles displayed in Fig. 1 illustrate the capabilities of the radars. The W-band reflectivity of APR [top row, shown only for illustration purposes as the article focuses on $(\mathrm{Ku}, \mathrm{Ka})$-band data] is highly sensitive to particles in the top of clouds, but heavily attenuated toward the surface (the surface echo disappears). On 2 December 2015 (the dates are indicated as labels in top row of Fig. 1 and separated by dashed red lines), $Z_{A, \mathrm{w}}$ was unavailable. The Ka band of APR, $Z_{A, \mathrm{Ka}}$ (row 2), has a sensitivity similar to that of $Z_{A, \mathrm{~W}}$, as can be seen in the cloud tops, and it is less attenuated. Owing to the tight collocation margins, there is a good agreement between $Z_{A, \mathrm{Ka}}$ and $Z_{D, \mathrm{Ku}}$ the $\mathrm{D} 3 \mathrm{R}$ observations at $\mathrm{Ku}$ band (row 3 ). The main differences appear in the profiles of the dual-wavelength ratios (DWR) $Z_{D, \mathrm{Ku}-\mathrm{Ka}}\left(\right.$ row 4 ) and $Z_{A, \mathrm{Ku}-\mathrm{Ka}}($ row 5): for D3R, since $Z_{D, \mathrm{Ka}}$ has less sensitivity than $Z_{D, \mathrm{Ku}}$, there are places with missing DWR in the top parts of $Z_{D, \mathrm{Ku}-\mathrm{Ka}}$; conversely, for APR, $Z_{A, \mathrm{Ku}}$ has less sensitivity than $Z_{A, \mathrm{Ka}}$ and there are empty spots in the top parts of $Z_{A, \mathrm{Ku}-\mathrm{Ka}}$ (above $6 \mathrm{~km}$ in the stratiform event of 12 November 2015$)$. The ground-based DWR $Z_{D, \mathrm{Ku}-\mathrm{Ka}}$ (row 4) shows how liquid scatterers increase the attenuation significantly. For instance, on 12 November 2015, for the first 90 profiles, $Z_{D, \mathrm{Ka}}$ is strongly attenuated above the melting layer (clearly visible with a bright band around $2 \mathrm{~km}$ of altitude), whereas for the next profiles, the attenuation of $Z_{D, \mathrm{Ka}}$ increases drastically from the surface upward, most likely due to liquid or mixed-phase precipitation. The presence of liquid precipitation can be inferred from the temperature (row 6 ) measured by CIT (position indicated by black dots in the top five panels). The DWR of APR (row 5) is less affected by attenuation since, above the melting layer, the attenuation is mostly caused by low-density frozen hydrometeors. Instead, higher values of $Z_{A, \mathrm{Ku}-\mathrm{Ka}}$, indicative of larger scatterers, show the growth of particles in the melting layer, for example, on 12 November and 2 December 2015. The bottom row displays the PSD obtained from 2DS and HVPS3 [denoted $N(D)$ with 

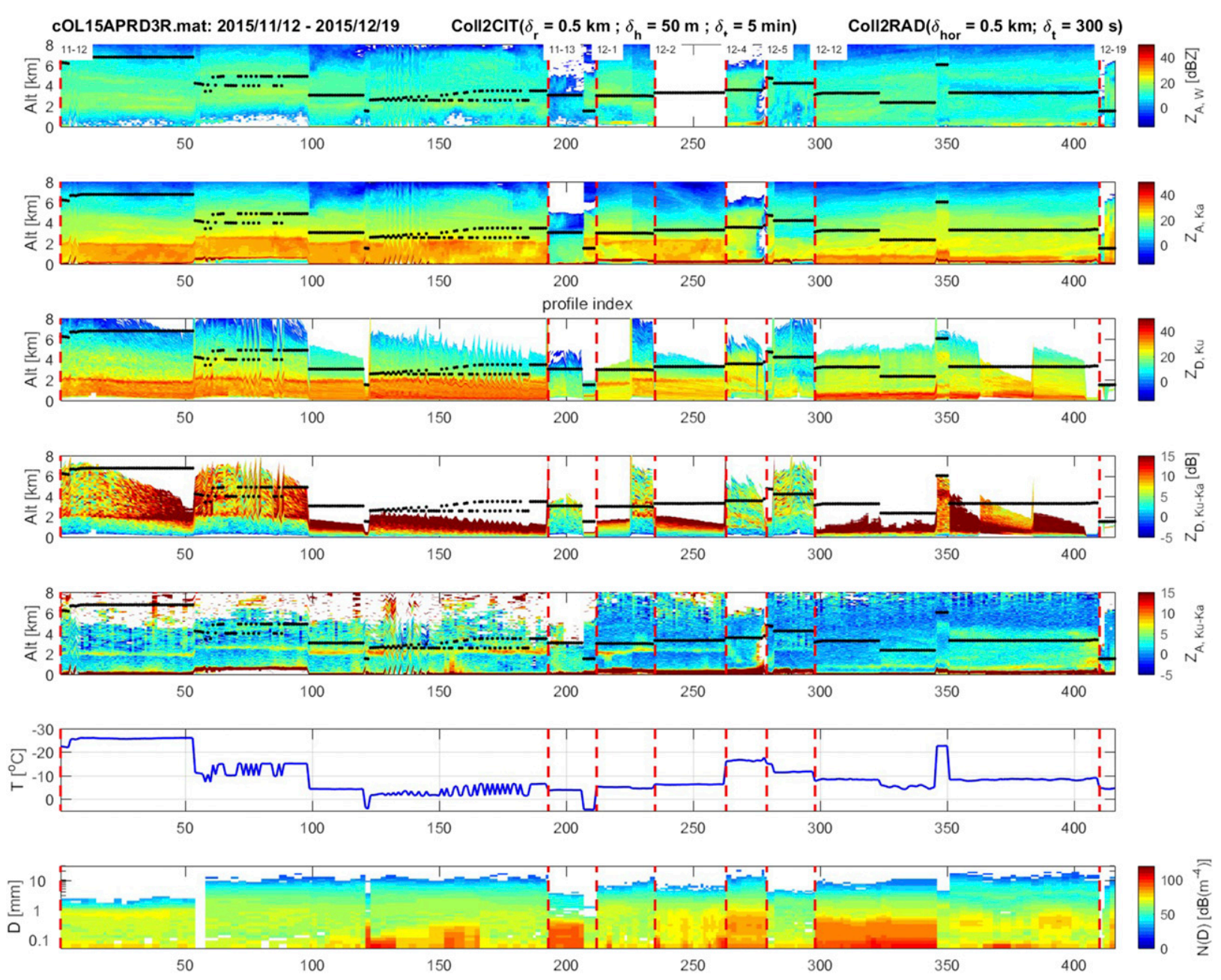

FIG. 1. Triple collocations APR-CIT-D3R during OLYMPEx. Radar profiles measured (first, second, and fifth rows) by APR3 and (third and fourth rows) by D3R: W-band $\left(Z_{A, \mathrm{~W}}\right)$ and Ka-band $\left(Z_{A, \mathrm{Ka}}\right)$ reflectivity from APR in the top two rows, Ku-band reflectivity $\left(Z_{D, \mathrm{Ku}}\right)$ from D3R in the third row; DWR $\left(Z_{\mathrm{Ku}-\mathrm{Ka}}\right)$ from D3R in the fourth row and APR in the fifth row. In situ measurements in the bottom two rows: air temperature in the sixth row and particle size distribution $N(D)$ derived from 2DS and HVPS3 vs the maximum particle size $D$ in the bottom row. The altitude of CIT is shown as black dots in rows 1 to 5, and the dates (month-day format) are labeled in the top row and separated by dashed red lines in all rows.

$D$ the maximum particle size] and shows the abundance of smaller frozen particles $\left(D<1 \mathrm{~mm}\right.$ and $\left.T<-7^{\circ} \mathrm{C}\right)$, for example, on 13 November 2015. Even though this triple-collocation example shows that D3R's Ka-band measurements are severely affected by attenuation, there are many more cases of D3R-CIT collocations where the attenuation is not as severe (more than 55000 and 19000 in GCPEx and OLYMPEx, respectively; see Fig. 4).

\section{Scattering calculations}

Particle images, measured in situ by the 2DS and HVPS3 probes, are processed to derive the distributions of particle sizes $N(D)$ and aspect ratios $R_{\mathrm{ASP}}(D)$, for $D$ ranging between $D_{\min }=0.1 \mathrm{~mm}$ and $D_{\max }=30 \mathrm{~mm}$
(Heymsfield et al. 2002b). In this article, the $D$ measured by 2DS and HVPS3 (two-dimensional imaging probes) is the maximum dimension.

Given an image from either HVPS or 2DS, for every particle with maximum dimension $D$, the aspect ratio $R_{\mathrm{ASP}}(D)$ is defined as $R_{\mathrm{ASP}}(D)=W(D) / D$, with $W(D)$ the maximum dimension in the direction orthogonal to $D$ (Korolev and Isaac 2003). Since every image generally contains multiple particles, the processing yields a set of values $\left[D, R_{\mathrm{ASP}}(D)\right]$ and similarly for $\left.[D, N(D)]\right\}$, which are integrated over $5 \mathrm{~s}$ to obtain an individual spectrum. Our objective is to use these measured spectra in a scattering model and compute unattenuated reflectivity factors that will be compared to collocated radar observations. These simulations (described in section 3a) 
depend crucially on the mass of the particles, which, however, was not measured. We will tackle this issue by making assumptions about the mass-size dependency of the particles (section $3 b$ ).

\section{a. Modeling approach assuming a fixed mass-size parameterization}

We assume that the MSP has a given form denoted $m(D)$. The corresponding reflectivity factors $Z_{F}\left(\mathrm{~mm}^{6} \mathrm{~m}^{-3}\right)$ at wavelength $\lambda$ is computed as (Doviak and Zrnić 1993)

$$
Z_{F}=\frac{\lambda^{4}}{\pi^{5}\left|K_{w}\right|^{2}} \int_{D_{\min }}^{D_{\max }} \sigma_{B}(\lambda, D) N(D) d D,
$$

where $\left|K_{w}\right| \approx 0.93$ is the reference dielectric factor of water chosen constant to ensure that the DWR $Z_{\mathrm{Ku}-\mathrm{Ka}}=Z_{\mathrm{Ku}}-Z_{a}$ tends to 0 in the Rayleigh limit of small particles, and $N(D)$ is the PSD measured in situ. The backscattering cross-section $\sigma_{B}$, which depends on the assumed MSP, is computed using a T-matrix code (Waterman 1971), where particles are represented as equivalent spheroids of maximum size $D$, with an oblateness ratio equal to the measured $R_{\mathrm{ASP}}(D)$. We assume that particles fall with their largest dimension nearly horizontal. However, such may not be the case in reality, for example, in the presence of turbulence or a strong electric field (Weinheimer and Few 1987). In such cases, large differences between $D$ (measured by $2 \mathrm{D}$-imaging probes) and the true maximum size of the three-dimensional particle can bias the volume of the circumscribing spheroid, the assumed density, and simulated scattering properties of the particles. Studies have shown that in such cases, it may be better to use the mean particle diameter (Hogan et al. 2012) or the disk-equivalent diameter, or to adjust the measured $D$ (von Lerber et al. 2017). These promising approaches are not used in the framework of this article because the measured regimes in GCPEx and OLYMPEx have small turbulence (without strong convection or thunderstorms), which limits possible discrepancies between the measured $D$ and the true maximum size of the particle. The effective refractive indices of the particles are computed via a Bruggeman approximation (Bruggeman 1935), and depend on the MSP, which sets the fraction of ice versus air in the particle approximation.

To characterize the microphysical properties of particles, bulk moments are used, namely the ice water content (IWC) $M\left(\mathrm{~g} \mathrm{~m}^{-3}\right)$, the mean mass-weighted diameter $D_{m}(\mathrm{~m})$, and the normalized diameter spread $S_{m}$ (unitless), with

$$
M=\int_{D_{\min }}^{D_{\max }} m(D) N(D) d D,
$$

$$
D_{m}=\mathbb{E}_{m}(D) \quad \text { and } \quad S_{m}=\frac{1}{D_{m}} \sqrt{\mathbb{E}_{m}\left[\left(D-D_{m}\right)^{2}\right]}
$$

where the expectation operator $\mathbb{E}_{m}(\cdot)$ is defined as

$$
\begin{aligned}
\mathbb{E}_{m}(y)= & \frac{1}{M} \int_{D_{\min }}^{D_{\max }} y(D) m(D) N(D) d D, \\
& \text { for any function } y(D) .
\end{aligned}
$$

In this article, even though the continuous notation is used for integrals [e.g., Eqs. (2) and (4)], in practice, they are evaluated as discrete sums via a trapezoidal quadrature rule.

\section{b. Uncertainties due to the MSP}

To quantify the effect of the uncertain mass of the particles, the simulations are perturbed by considering 56 different MSPs, which are power laws denoted $\left\{P_{k}\right\}_{k=1, \ldots, 56}$ (Pruppacher and Klett 1996). More explicitly, if the parameterization index is written as $k=8(j-1)+i$,

$$
m_{k}(D)=a_{i} D^{b_{j}}, \quad \text { for } i=1, \ldots, 8 \text { and } j=1, \ldots, 7,
$$

with $a_{1}=0.005, a_{2}=0.0010, a_{3}=0.0019, a_{4}=0.0037$, $a_{5}=0.0071, a_{6}=0.0139, a_{7}=0.0269, a_{8}=0.0524$ in cgs units (i.e., $a_{i}$ is in $\mathrm{g} \mathrm{cm}^{-b_{j}}$ ), and $b_{1}=1.01, b_{2}=1.34, b_{3}=$ $1.67, b_{4}=2, b_{5}=2.34, b_{6}=2.67$ and $b_{7}=3$. One can convert the prefactors to MKS units as follows $a_{i,(\mathrm{MKS})}=a_{i,(\mathrm{cgs})} 10^{2 b_{j}-3}$, where the corresponding $m, D$, and $a_{i,(\mathrm{MKS})}$ would be expressed in kilograms, meters, and $\mathrm{kg} \mathrm{m}^{-b_{j}}$, respectively. All these $m(D)$ relationships have merits of their own as they were generally derived from field or laboratory experiments. In particular, $P_{56}$ (with $a=0.0524$ and $b=3$ ) corresponds to assuming a constant density of $0.1 \mathrm{~g} \mathrm{~cm}^{-3}$, which is common in GPM algorithms (Liao et al. 2005; Grecu et al. 2011). Based on observational evidence, the exponent $b$ should range between $\sim 1.7$ and 3 (Pruppacher and Klett 1996; Haddad et al. 2017). However, in this article, a wider range of values is considered, with $b$ as low as 1.01 , to test whether such coefficients still produce accurate scattering computations. This approach is similar to the one of Fontaine et al. (2014), who assumed $b$ as low as 1.04. Thus, for every in situ measurement, the T-matrix simulations produce 56 realizations of reflectivities at $\mathrm{Ku}$ and $\mathrm{Ka}$ band, and moments $\left(M, D_{m}, S_{m}\right)$. Table 2 shows the effect of the MSP uncertainty on the simulations. Given a parameterization $P_{k}$, a CIT record time $t$, and a variable $X_{k}$ (reflectivity or moment in decibels), the spread of $X_{k}$ at time $t$ due to the MSP perturbation is 
TABLE 2. Effect of the MSP perturbation on the simulated radar reflectivities and bulk moments. The metric $s_{X}$ is the range of variation of variable $X$, as defined in Eq. (6) and expressed in $\mathrm{dB}$ (statistics of $s_{X}$ smaller than $0.5 \mathrm{~dB}$ are rounded off to $0 \mathrm{~dB}$ ). The slight differences between GCPEx and OLYMPEx results are due to the differences between the measured PSDs.

\begin{tabular}{|c|c|c|c|c|c|c|c|}
\hline & & \multicolumn{3}{|c|}{$X=$ forward product } & \multicolumn{3}{|c|}{$X=$ bulk moment } \\
\hline & & $Z_{\mathrm{Ku}}(\mathrm{dB} Z)$ & $Z_{\mathrm{Ka}}(\mathrm{dB} Z)$ & $Z_{\mathrm{Ku}-\mathrm{Ka}}(\mathrm{dB})$ & $M\left(\mathrm{~dB} \mathrm{~g} \mathrm{~m}^{-3}\right)$ & $D_{m}(\mathrm{~dB} \mathrm{~mm})$ & $S_{m}(\mathrm{~dB})$ \\
\hline \multirow[t]{2}{*}{ GCPEx } & $\min \left(s_{X}\right)$ & 43 & 42 & 0 & 23 & 0 & 0 \\
\hline & $\max \left(s_{X}\right)$ & 58 & 58 & 15 & 37 & 12 & 7 \\
\hline \multirow[t]{2}{*}{ OLYMPEX } & $\min \left(s_{X}\right)$ & 43 & 45 & 0 & 24 & 0 & 0 \\
\hline & $\min \left(s_{X}\right)$ & 57 & 58 & 26 & 39 & 18 & 11 \\
\hline
\end{tabular}

$$
s_{X}(t)=\max \left[X_{k}(t)\right]-\min \left[X_{k}(t)\right]
$$

Table 2 confirms that the MSP perturbation affects mostly the IWC and the reflectivities. Since the MSP perturbation modifies neither the shape nor size of the scatterers, the DWR, $D_{m}$ and $S_{m}$ are marginally affected by the MSP perturbation. The robustness of $D_{m}$ and $S_{m}$ comes also from their definition as mass-normalized averages [see Eq. (4)].

\section{Optimal MSPs constrained by collocated radar observations}

Collocated radar observations are now used to evaluate the skills of the various simulations.

\section{a. Screening radar profiles for liquid attenuation}

First, the radar profiles are screened to eliminate those severely attenuated by liquid particles. The attenuation by frozen particles is not addressed because 1) GCPEx and OLYMPEx are devoid of high-density hydrometeors (such as hail or graupel) and the attenuation at $\mathrm{Ku}$ and $\mathrm{Ka}$ bands by low-density snow/ice is not as strong as the liquid attenuation, and 2) the attenuation by frozen particles depends on the yet unknown masses of the scatterers. As explained in appendix A, the correction uses collocated profiles of temperature from MERRA ("MERRA300. prod.assim.inst3_3d_asm_Cp", product), and $k-Z$ relationships derived from GCPEx and OLYMPEx PSDs. The resulting liquid pathintegrated attenuation $\left(\right.$ PIA $_{\text {liq }}$ ) between the radar and CIT allows us to eliminate all the collocated samples where PIA $_{\text {liq }}>$ PIA $_{\max }=0.5 \mathrm{~dB}$. The liquid water content (LWC) measured by the King probe (designed to measure $\left.\mathrm{LWC} \in[0.02,5.0] \mathrm{g} \mathrm{m}^{-3}\right)$ is also used to eliminate all CIT records where LWC $>5 \times 10^{-2} \mathrm{~g} \mathrm{~m}^{-3}$.

\section{b. MSP optimization}

For any MSP $P_{k}$, the absolute error $\Delta_{\mathrm{Ku}, \mathrm{Ka}}$ between the reflectivities $\left(Z_{k, \mathrm{Ku}}, Z_{k, \mathrm{Ka}}\right)$ simulated by T matrix, and, collocated reflectivity measurements $\left(Z_{\mathrm{obs}, \mathrm{Ku}}\right.$, $\left.Z_{\text {obs, Ka }}\right)$ is

$$
\Delta_{\mathrm{Ku}, \mathrm{Ka}}=\max \left(\left|Z_{\mathrm{obs}, \mathrm{Ku}}-Z_{k, \mathrm{Ku}}\right|,\left|Z_{\mathrm{obs}, \mathrm{Ka}}-Z_{k, \mathrm{Ka}}\right|\right) \text {. }
$$

The "optimal MSPs" (OMSP) are those for which $\Delta_{\mathrm{Ku}, \mathrm{Ka}} \leq \Delta_{\max }=1.5 \mathrm{~dB}$. The threshold $\Delta_{\max }$ constrains the forward simulations, while accounting for calibration errors of APR and D3R. Such a strict threshold should also eliminate samples contaminated by reflections from the ground (APR data) or the CIT aircraft.

\section{c. Retrieved bulk moments $\left(M, D_{m}, S_{m}\right)$ and references}

The retrieved quantities are the bulk moments $\left(M, D_{m}, S_{m}\right)$ of the OMSPs. One difficulty is to find references for these moments, that is, in situ measurements, which do not depend on the MSP assumptions. Ideally, one would want to use the true values of these moments. However, as shown by Eqs. (2)-(4), it requires knowledge of the true $m(D)$ relationship, which is unknown. Instead of true values, reference values are used to estimate the expected magnitude of the bulk moments. For the IWC, the reference is the total water content $M_{\mathrm{Nev}}$ at negative temperatures, as measured by the Nevzorov probe (designed for $M_{\mathrm{Nev}} \in[0.02,1.5] \mathrm{g} \mathrm{m}^{-3}$ ). Although the Nevzorov probe can occasionally underestimate the true total water content (see, e.g., Korolev et al. 2013), it is the only available independent measurement of IWC. The reference for the mean particle diameter is chosen as the median-volume diameter $D_{0}$, which is the solution of (Brandes et al. 2004)

$$
\int_{D_{\min }}^{D_{0}} v(D) N(D) d D=\int_{D_{0}}^{D_{\max }} v(D) N(D) d D,
$$

where the volume is defined as

$$
v(D)=\frac{\pi}{6} D^{3} R_{\mathrm{ASP}}(D) .
$$

The definition of $D_{0}$, is of course different than the definition of $D_{m}$ [see Eq. (3)]. However, as detailed in appendix B, $D_{0}$ is a better (high correlation and low bias) 

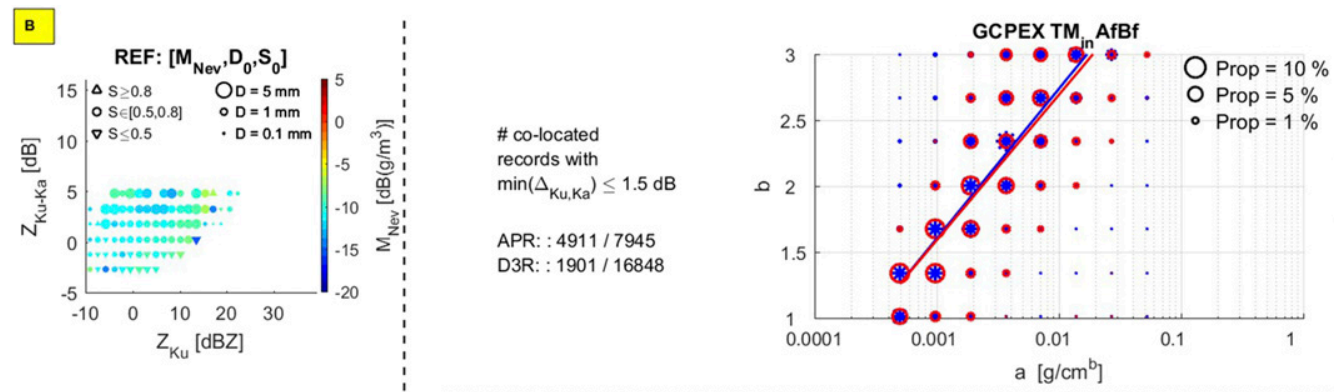

APR: : $b=0.114 \mathrm{a}_{\mathrm{dB}}+5.008$ D3R: : $b=0.110 a_{d B}+4.896$
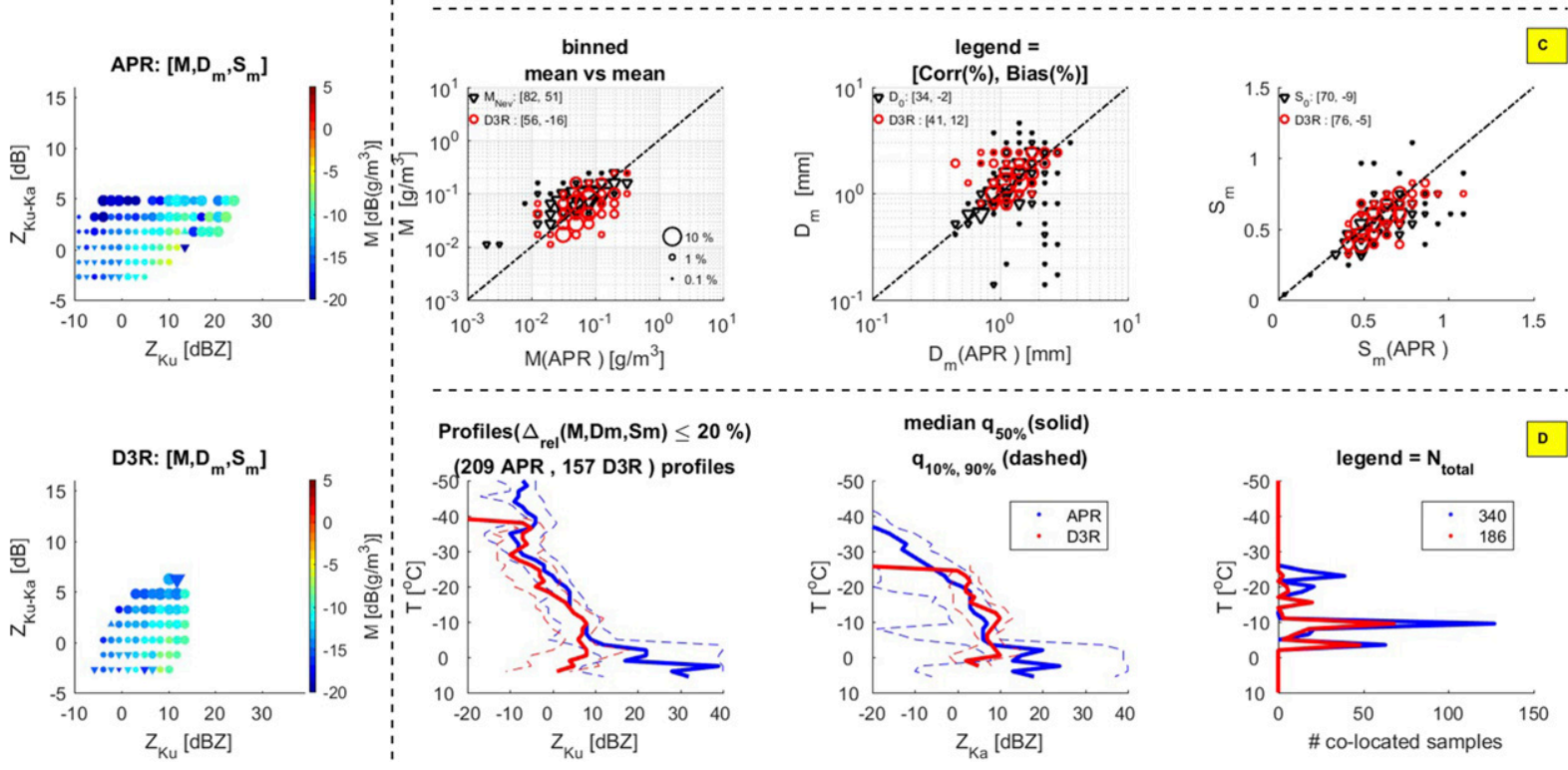

FIG. 2. Retrieval dashboard from triple collocations in GCPEx (APR vs D3R). (a) Distribution of optimal MSPs as a function of ( $a, b$ ) (marker size represents the occurrence frequency, and solid line is fit $b_{\mathrm{fit}}=K_{1} a_{\mathrm{dB}}+K_{2}$ for OMSP "diagonal"). (b) Mean values, conditional to $\left(Z_{\mathrm{Ku}}, Z_{\mathrm{Ku}-\mathrm{Ka}}\right)$ measured by (top),(middle) APR and (bottom) D3R, of bulk moments [references $\left(M_{\mathrm{Nev}}, D_{0}, S_{0}\right)$ in top row, retrievals $\left(M, D_{m}, S_{m}\right)$ in bottom two rows]: IWC $M$ or $M_{\mathrm{Nev}}$ (marker color), mean diameter $D_{m}$ or $D_{0}$ (marker size), and spread $S_{m}$ or $S_{0}$ (marker type). (c) Scatterplots comparing bulk moments [(left) $M$, (center) $D_{m}$, and (right) $S_{m}$ ] retrieved from APR (horizontal axis) to those from D3R and references (vertical axis, marker size represents the occurrence frequency). (d) Profiles where retrievals from APR and D3R agree within $20 \%$ of relative error: vertical profiles of quantiles of (left) $Z_{\mathrm{Ku}}$ and (center) $Z_{\mathrm{Ka}}$, and (right) number of samples.

reference than the PSD-weighted or volume-weighted mean diameters. For the normalized spread $S_{m}$, the reference is $S_{0}=\sqrt{\mathbb{E}_{V}\left[\left(D-D_{0}\right)^{2}\right]} / D_{0}$, the volume-weighted spread about $D_{0}$, where $\mathbb{E}_{V}(\cdot)$ is defined as

$$
\begin{aligned}
\mathbb{E}_{V}(y)= & \frac{1}{V} \int_{D_{\min }}^{D_{\max }} y(D) v(D) N(D) d D, \\
& \text { for any function } y(D), \\
V= & \int_{D_{\min }}^{D_{\max }} v(D) N(D) d D .
\end{aligned}
$$

\section{d. Microphysical dashboard: Illustration using triple collocations APR-CIT-D3R}

We now introduce the retrieval dashboard used to analyze the OMSPs: it is a figure (see, e.g., Fig. 2) consisting of four panels (labeled by yellow boxes) that allow us to jointly study the parameters of the OMSPs (Fig. 2a), the collocated radar reflectivities (Figs. 2b,d), the bulk moments (Figs. 2b,c), and to compare various retrievals. The dashboard is illustrated in Fig. 2 for OMSPs obtained using triple-collocation data from GCPEx, that is, $(\mathrm{Ku}, \mathrm{Ka})$ data from APR and D3R in cases where APR, CIT, and D3R measurements are collocated.

\section{1) Figure 2A: Statistics OF THE OMSP PARAMETERS}

Figure 2a shows statistics of the OMSP parameters. As indicated on the left of the graph, the MSP perturbation allows to accurately simulate collocated $\mathrm{Ku}$ and Ka observations for 4911 APR samples and 1901 D3R samples (i.e., for each of these collocated observations, at least one of the assumed MSPs produces $\mathrm{Ku}$ and $\mathrm{Ka}$ 
reflectivities such that $\left.\Delta_{\mathrm{Ku}, \mathrm{Ka}} \leq 1.5 \mathrm{~dB}\right)$. All the MSPs for which $\Delta_{\mathrm{Ku}, \mathrm{Ka}} \leq 1.5 \mathrm{~dB}$ (a single collocated radar observation may have multiple MSP simulations that are accurate) are used to compute the frequency of occurrence of each OMSP, which is plotted as a function of the parameters $(a, b)$ of the power law (marker size proportional to the frequency of occurrence). None of the MSPs clearly dominates the others, since the highest score is lower than $10 \%$. On the other hand, if all parameterizations were equally likely to be optimal, each would have a score of $1 / 56 \sim 2 \%$. Instead, there are preferred MSPs, which are clustered along a line (hereinafter named the OMSP "diagonal," for ease of reference) shown as a solid line and defined by $b \sim 0.114 a_{\mathrm{dB}}+5.008$ for APR $(b \sim$ $0.110 a_{\mathrm{dB}}+4.896$ for D3R), where $a_{\mathrm{dB}}=10 \log _{10}(a)$. There is a close resemblance between the APR- and D3R-based OMSPs, as expected from the triple collocation (APR and D3R observe the same volume) and the fact that the light precipitation in GCPEx limited the impact of attenuation on the radar observations.

\section{2) FIGURE 2B: OMSP BULK MOMENTS}

\section{$\left(M, D_{m}, S_{m}\right)$ VERSUS RADAR OBSERVATIONS}

Figure $2 \mathrm{~b}$ shows the conditional mean of the bulk moments as a function of the collocated radar observations $\left(Z_{\mathrm{Ku}}, Z_{\mathrm{Ku}-\mathrm{Ka}}\right)$. The top row shows the distribution of the references $\left(M_{\mathrm{Nev}}, D_{0}, S_{0}\right)$ as a function of collocated $\left(Z_{\mathrm{Ku}}, Z_{\mathrm{Ku}-\mathrm{Ka}}\right)$ from APR. The second and third rows show the retrieved $\left(M, D_{m}, S_{m}\right)$ as a function of collocated $\left(Z_{\mathrm{Ku}}, Z_{\mathrm{Ku}-\mathrm{Ka}}\right)$ from APR and D3R, respectively. The IWC $\left(M_{\mathrm{Nev}}\right.$ or $M$ in logarithmic scale) and the mean diameter $\left(D_{0}\right.$ or $\left.D_{m}\right)$ set the color and the size of the markers, respectively. Different markers indicate small (downward triangle)-, moderate (circle)-, and large (upward triangle)-diameter spreads $\left(S_{0}\right.$ or $\left.S_{m}\right)$. The various plots of Fig. $2 \mathrm{~b}$ show that 1 ) the $M$ retrieved for $Z_{\mathrm{Ku}} \leq$ $5 \mathrm{dBZ}$ are slightly lower than $M_{\mathrm{Nev}}$, most likely due to the limited sensitivity of the Nevzorov probe, 2) larger particles correspond to larger $Z_{\mathrm{Ku}-\mathrm{Ka}}$, and 3) almost all retrieved spreads $S_{m}$ correspond to low or moderate spreads $\left(S_{m} \leq\right.$ 0.8 , and similarly for $S_{0}$ ).

\section{3) FIGURE 2C: INTERCOMPARISON OF RETRIEVED BULK MOMENTS $\left(M, D_{m}, S_{m}\right)$}

Figure 2c compares the APR-based retrievals (horizontal axis) to the D3R-based retrievals and to the reference moments (both on vertical axis, in red and black, respectively). To build these plots, the values of $\left(M, D_{m}, S_{m}\right)$ are binned as a function of the observed $\left(Z_{\mathrm{Ku}}, Z_{\mathrm{Ku}-\mathrm{Ka}}\right)$ and the local temperature $T$. Then, for every bin of the conditioning $\left(Z_{\mathrm{Ku}}, Z_{\mathrm{Ku}-\mathrm{Ka}}, T\right)$ hypercube, the mean of the retrieved $\left(M, D_{m}, S_{m}\right)$ and $\left(M_{\mathrm{Nev}}, D_{0}, S_{0}\right)$ are computed. Using the same conditioning hypercube allows us to compare the various retrievals in scatterplots such as those of Fig. 2c ( $M$ in the left column, $D_{m}$ in the middle column, and $S_{m}$ in the right column). The sizes of the markers are proportional to the frequency of occurrence. The legend provides the correlation coefficient $C$ (in \%) and the relative bias $B$ between the variables [given two positive variables $X$ and $Y$, the bias between $X_{\mathrm{dB}}=10 \log _{10}(X)$ and $Y_{\mathrm{dB}}=10 \log _{10}(Y)$ is $B_{0}=\mathbb{E}\left(Y_{\mathrm{dB}}-X_{\mathrm{dB}}\right)$, and the relative bias is defined as $B=100\left(10^{0.1 B_{0}}-1\right)$, in \%]. There is a good agreement between APR- and D3R-based retrievals of all moments (clustering of points about the diagonal dashed line and small biases). The retrieved moments are also in agreement with their reference values. Hence, for this triple-collocation case, the retrievals are relatively insensitive to the platform (airborne or ground based) from which the radar measurements are acquired. This result is also the sign of a suitable mutual calibration between APR and D3R.

\section{4) Figure 2D: RADAR PROFILES OF CONSISTENT APR/D3R RETRIEVALS OF $\left(M, D_{m}, S_{m}\right)$}

Figure $2 \mathrm{~d}$ provides a broader context for the environment in which APR- and D3R-based retrievals agree. In other words, this panel tries to check, in cases where both the radar observations and the retrievals match at the collocation site, if the radar profiles from APR and D3R match as well. The first step is to select all the bins of the conditioning $\left(Z_{\mathrm{Ku}}, Z_{\mathrm{Ku}-\mathrm{Ka}}, T\right)$ hypercube where APR and D3R retrievals of $\left(M, D_{m}, S_{m}\right)$ jointly agree (less than $20 \%$ of relative error). Then, all the corresponding collocated samples are collected and their distribution is plotted as a function of the local $T$ measured by the CIT (right column). The last step is to collect the corresponding profiles of reflectivity and temperature (from MERRA) to compute contour-frequency-by-temperature diagrams (CFTDs), which are histograms of reflectivity at a given temperature. The envelopes of the CFTDs of $Z_{\mathrm{Ku}}$ and $Z_{\mathrm{Ka}}$ versus temperature are shown in the left and center columns, respectively (the median profile is plotted as a solid line, while the $10 \%$ and $90 \%$ quantiles are plotted as dashed lines). These graphs show that the collocated samples where APR and D3R agree are mostly at temperatures warmer than $-25^{\circ} \mathrm{C}$, where a resemblance can be observed between APR and D3R profiles of reflectivity. The limited sensitivity of D3R's Ka band $(\sim 5 \mathrm{dBZ})$ explains the lack of data for $T \leq-25^{\circ} \mathrm{C}$.

\section{e. Microphysical dashboard for triple collocations from OLYMPEX}

Figure 3 shows the retrieval dashboard for triple collocations from OLYMPEx. These results correspond to the profiles shown in Fig. 1, where the liquid PIA and 

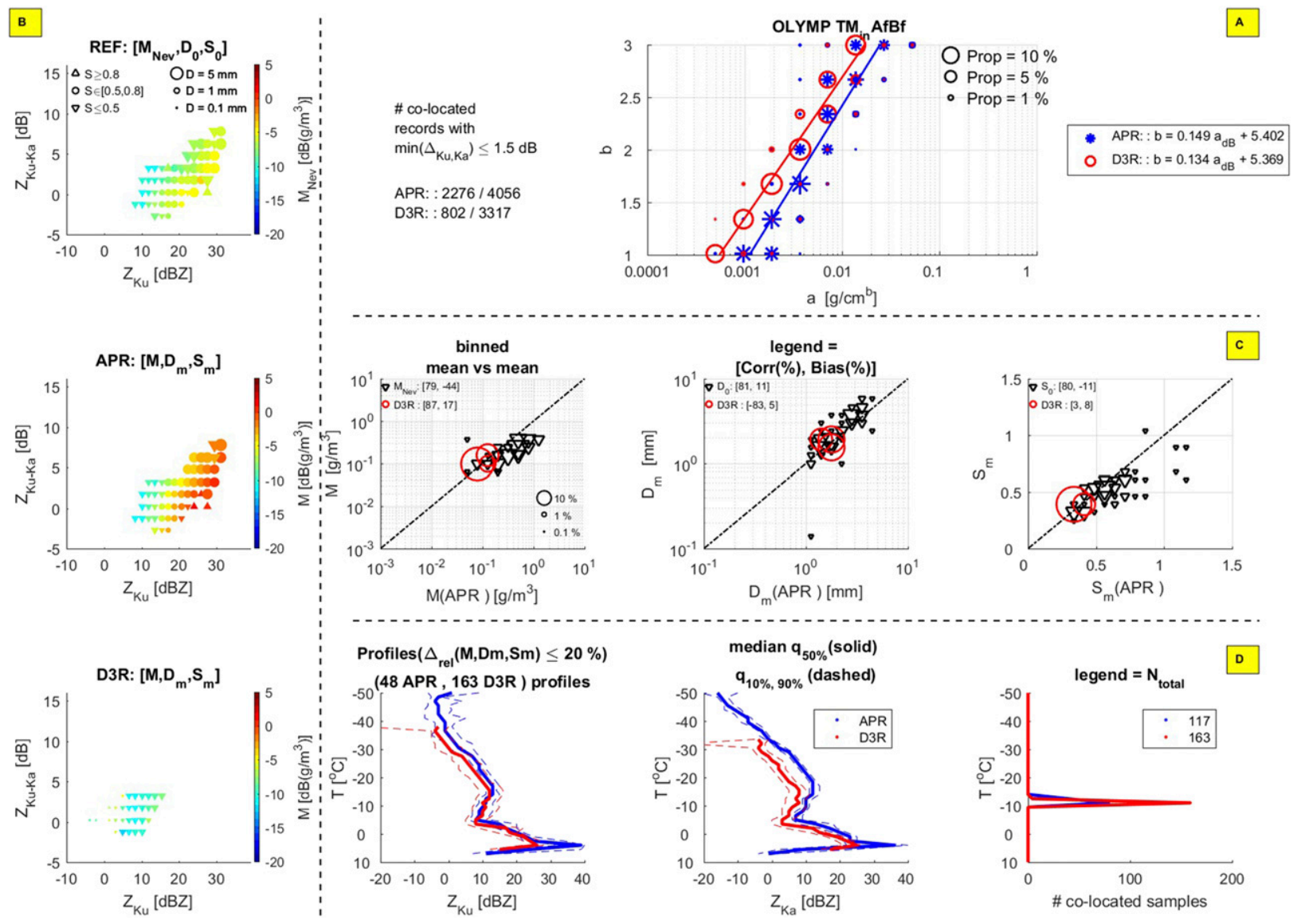

FIG. 3. Retrieval dashboard from triple collocations in OLYMPEx (APR vs D3R). (a) Distribution of OMSPs as a function of ( $a, b$ ) (marker size represents the occurrence frequency, and solid line is fit for OMSP "diagonal"). (b) Mean values, conditional to ( $Z_{\mathrm{Ku}}$, $Z_{\mathrm{Ku}-\mathrm{Ka}}$ ) measured by (top),(middle) APR and (bottom) D3R, of bulk moments (references in top row, retrievals in middle and bottom): IWC $M$ or $M_{\mathrm{Nev}}$ (marker color), mean diameter $D_{m}$ or $D_{0}$ (marker size), and spread $S_{m}$ or $S_{0}$ (marker type). (c) Scatterplots comparing bulk moments [(left) $M$, (center) $D_{m}$, and (right) $S_{m}$ ] retrieved from APR (horizontal axis) to those from D3R and references (vertical axis, marker size represents the occurrence frequency). (d) Profiles where retrievals from APR and D3R agree within $20 \%$ of relative error: vertical profiles of quantiles of (left) $Z_{\mathrm{Ku}}$ and (center) $Z_{\mathrm{Ka}}$, and (right) number of samples.

local LWC are lower than the thresholds described in section 4a. Figure 3a shows that there are half as many usable samples than in the GCPEx case due to more severe liquid attenuation (2276 APR and 802 D3R samples in OLYMPEx vs $4911 \mathrm{APR}$ and $1901 \mathrm{D} 3 \mathrm{R}$ samples in GCPEx). The preferential MSPs are still clustered around a diagonal of the $(a, b)$ plane; however, this diagonal is different from the diagonal in the GCPEx collocations (Fig. 2). There are also differences between APR- and D3R-based diagonals. These discrepancies are due to differences in the observed reflectivities, which can be seen in Fig. 3b: the APR observations (top two rows) occupy a larger domain of the $\left(Z_{\mathrm{Ku}}, Z_{\mathrm{Ku}-\mathrm{Ka}}\right)$ plane than the D3R observations, particularly for $Z_{\mathrm{Ku}} \geq 20 \mathrm{~dB} Z$. A comparison between retrieved microphysics in Fig. 3c shows a good agreement between retrievals and with the references.
The saturation of the Nevzorov probe for larger IWC can be seen through the negative bias between $M_{\mathrm{Nev}}$ and the retrieved $M$. Figure $3 \mathrm{~d}$ shows a remarkable resemblance between profiles of $Z_{\mathrm{Ku}}$ and $Z_{\mathrm{Ka}}$ measured by APR and D3R (all from 5 December 2015; see Fig. 1), which again comforts the idea of a suitable cross calibration between the two radars.

While all the dashboards discussed so far are built using an "observation" hypercube $\left(Z_{\mathrm{Ku}}, Z_{\mathrm{Ku}-\mathrm{Ka}}, T\right)$, one could also build a dashboard conditioned by other parameters. For instance, with a "thermodynamic" hypercube $[(T, \mathrm{RH}, \mathrm{EDR})$ with $\mathrm{RH}$ the relative humidity with respect to ice, and EDR the eddy dissipation rate], one could compare retrievals from single- and dual-frequency radar observations, or from non-Doppler and Doppler radar observations. 

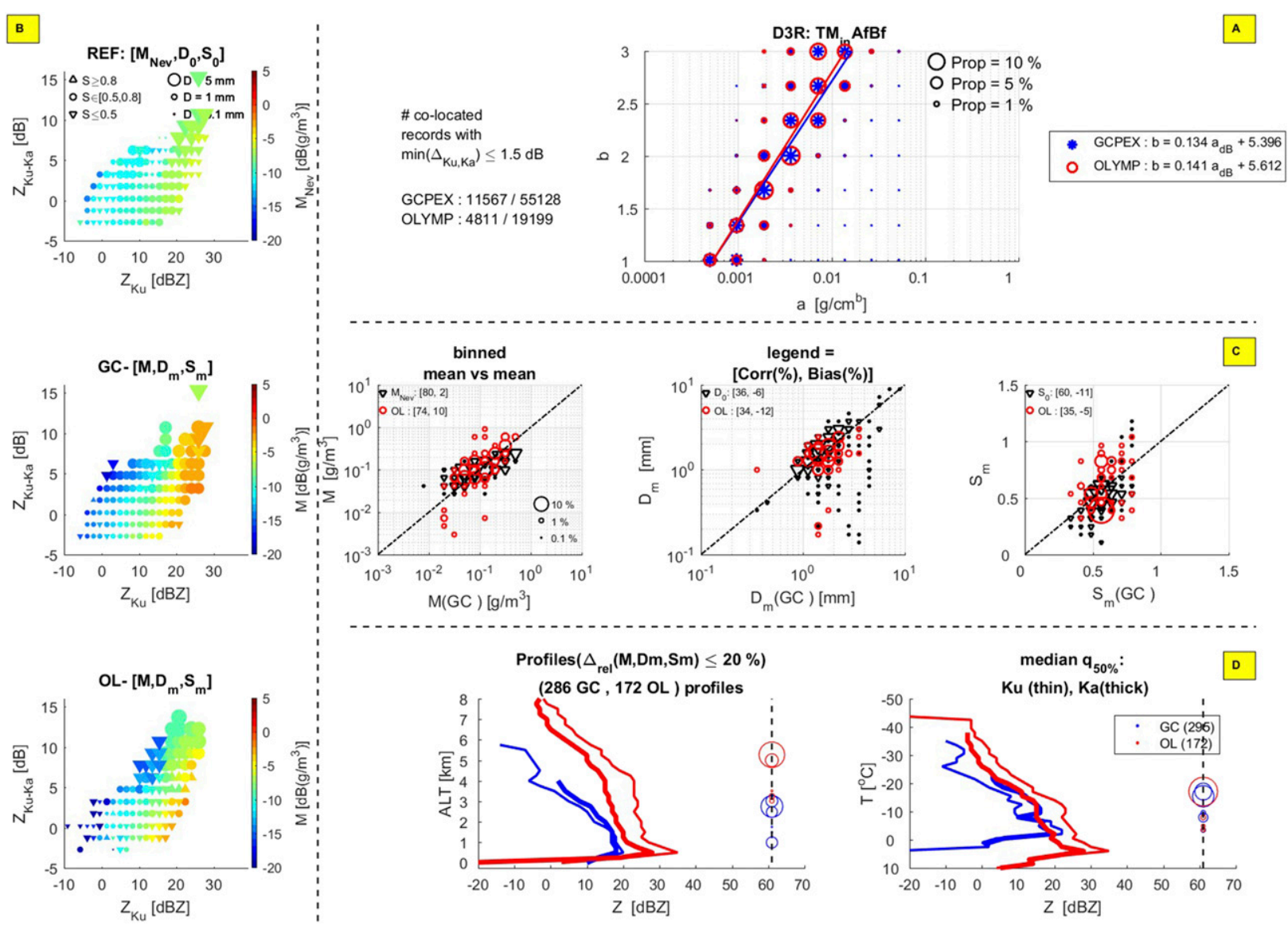

FIG. 4. Retrievals from D3R (Ku, Ka) observations (GCPEx vs OLYMPEx). (a) Distribution of OMSPs as a function of ( $a, b)$ (marker size represents the occurrence frequency, and solid line is fit for OMSP "diagonal"). (b) Mean values of bulk moments [(top) references, (middle),(bottom) retrievals], conditional to $\left(Z_{\mathrm{Ku}}, Z_{\mathrm{Ku}-\mathrm{Ka}}\right)$ measured by D3R in (top),(middle) GCPEx and (bottom) OLYMPEx: IWC (marker color), mean diameter (marker size), and spread (marker type). (c) Scatterplots comparing bulk moments retrieved from D3RGCPEx (horizontal axis) to those from D3R-OLYMPEx and references (vertical axis, marker size represents the occurrence frequency). (d) Profiles where retrievals from D3R-GCPEx and D3R-OLYMPEx agree within 20\% of relative error: profiles, as a function of (left) altitude and (right) temperature of the median of $Z_{\mathrm{Ku}}$ (thick line) and $Z_{\mathrm{Ka}}$ (thin line), and number of collocated samples (circles with sizes representing the number of samples).

\section{Comparison between GCPEx and OLYMPEx retrievals}

In this section, retrievals from GCPEx are compared to those from OLYMPEx to study the sensitivity of the microphysical retrievals to the meteorological regime.

\section{a. OMSPs constrained by collocated D3R observations: GCPEx versus OLYMPEX}

First, all acceptable D3R observations from GCPEx and OLYMPEx are used, separately, to constrain T-matrix simulations. Figure 4a shows that many more samples are accurately simulated in GCPEx than in OLYMPEx (more than $16000 \mathrm{vs} \sim 4800$ ). This results from the lower impact of attenuation on the radar observations in GCPEx (lighter precipitation) than in OLYMPEx. Similar to Figs. 2 and 3, the preferential MSPs are mostly along a slanted line of the $(a, b)$ plane, and the OMSP diagonals of GCPEx and OLYMPEx are almost identical. D3R observations in both field campaigns occupy the same region of the $\left(Z_{\mathrm{Ku}}, Z_{\mathrm{Ku}-\mathrm{Ka}}\right)$ space (see Fig. $4 \mathrm{~b}$, second row for GCPEx and bottom row for OLYMPEx). The Nevzorov probe does not capture the higher values of IWC seen in GCPEx, most likely due to saturation of the probe. Figure $4 \mathrm{c}$ shows a good agreement between GCPEx- and OLYMPEx-trained retrievals of $M$ and $D_{m}$. For $S_{m}$, the correlation between GCPEx and OLYMPEx results is weaker. Thus, while the retrievals of the lower-order moments seem robust to the change in training dataset, the retrieved spread seems to depend on the meteorological regime being measured. Figure $4 \mathrm{~d}$ is slightly modified compared to Figs. $2 \mathrm{~d}$ and $3 \mathrm{~d}$. It still shows vertical profiles of reflectivity for cases where GCPEx 

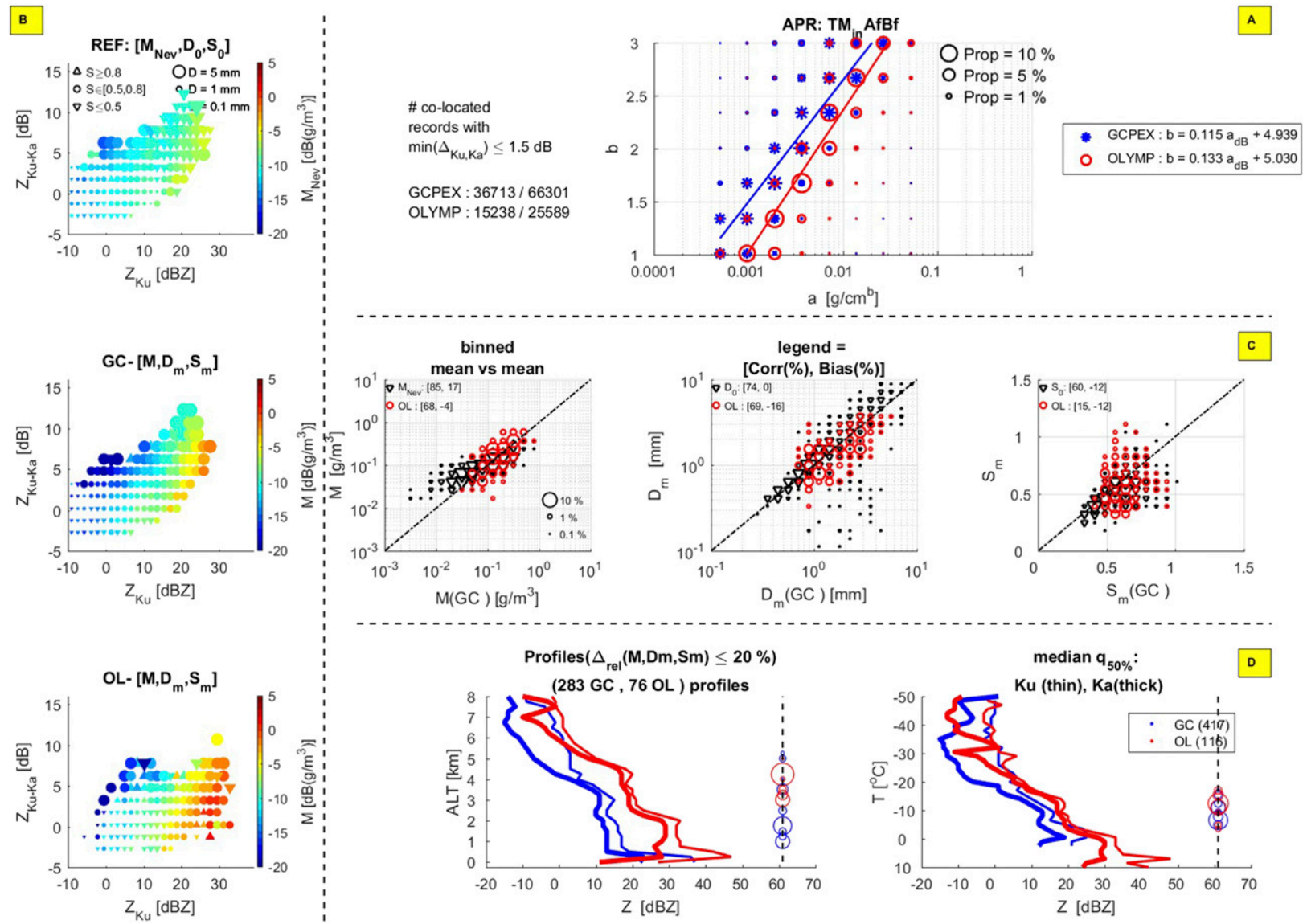

FIG. 5. Retrievals from APR (Ku, Ka) observations (GCPEx vs OLYMPEx). (a) Distribution of OMSPs as a function of ( $a, b)$ (marker size represents the occurrence frequency, and solid line is fit for OMSP "diagonal"). (b) Mean values of bulk moments [(top) references, (middle),(bottom) retrievals], conditional to $\left(Z_{\mathrm{Ku}}, Z_{\mathrm{Ku}-\mathrm{Ka}}\right)$ measured by APR in (top),(middle) GCPEx and (bottom) OLYMPEx: IWC (marker color), mean diameter (marker size), and spread (marker type). (c) Scatterplots comparing bulk moments retrieved from APRGCPEx (horizontal axis) to those from APR-OLYMPEx and references (vertical axis, marker size represents the occurrence frequency). (d) Profiles where retrievals from APR-GCPEx and APR-OLYMPEx agree within 20\% of relative error: profiles, as a function of (left) altitude and (right) temperature of the median of $Z_{\mathrm{Ku}}$ (thick line) and $Z_{\mathrm{Ka}}$ (thin line), and number of collocated samples (circles with sizes representing the number of samples).

and OLYMPEx retrievals agree well (less than $20 \%$ relative error for all bulk moments); however, the left column shows the median profile of $Z_{\mathrm{Ku}}$ (thin line) and $Z_{\mathrm{Ka}}$ (thick line) as a function of the altitude [similar to a contourfrequency-by-altitude diagram (CFAD)], whereas the right column shows the same profiles but as a function of temperature (CFTD). In both plots, the vertical distribution of the collocated samples (equivalent to the histograms shown in the right column of Figs. $2 d$ and $3 d$ ) is shown as circles, with sizes proportional to the number of collocated samples (the alternative would have been to plot one distribution vs $T$ and another one vs the altitude, which would clutter Fig. 4d). The CFAD representation hardly shows any resemblance between GCPEx and OLYMPEx: the samples in GCPEx and OLYMPEx are located at different altitudes (red circles for OLYMPEx mostly above $3 \mathrm{~km}$, whereas the blue circles for GCPEx are all below $3.5 \mathrm{~km}$ ), and the reflectivities from OLYMPEx are significantly higher (more than $10 \mathrm{~dB}$ ) than those from GCPEx. On the other hand, the CFTD representation shows that the collocated samples are at the same temperatures (overlapping circles), and there is a high resemblance between Ka-band profiles for $T \in[-25,-8]^{\circ} \mathrm{C}$.

\section{b. OMSPs constrained by collocated APR observations: GCPEx versus OLYMPEx}

Figure 5 displays a similar dashboard (GCPEx vs OLYMPEx) built using collocated APR observations. Figure $5 \mathrm{~b}$ clearly illustrates the correlation between retrieved particle size and DWR $Z_{A, \mathrm{Ku}-\mathrm{Ka}}$, and, the dependency of $M$ on both $Z_{A, \mathrm{Ku}}$ and $Z_{A, \mathrm{Ku}-\mathrm{Ka}}$. While the 
TABLE 3. Global and local sensitivities to the MSP space. Effect of quantization: the various MSP sets are "AfBf" (fine sampling, chosen as baseline), "AcBc" (coarse sampling), "AuBf" [fixed prefactor $a$ in $m(D)=a D^{b}$ ], "AfBu" (fixed exponent $b$ ), and "AuBu" (fixed $a=$ $0.0037 \mathrm{~g} \mathrm{~cm}^{-1.67}$ and $b=1.67$ ). For a local sensitivity analysis around "AuBu," the following sets are considered: "AmBu" (fixed $a=$ $0.0019 \mathrm{~g} \mathrm{~cm}^{-1.67}$ and $b=1.67$ ), "ApBu" (fixed $a=0.0071 \mathrm{~g} \mathrm{~cm}^{-1.67}$ and $b=1.67$ ), "AuBm" (fixed $a=0.0037 \mathrm{~g} \mathrm{~cm}^{-1.34}$ and $b=1.34$ ), and "AuBp" (fixed $a=0.0037 \mathrm{~g} \mathrm{~cm}^{-2}$ and $b=2$ ). APR observations from OLYMPEx are used to constrain T-matrix simulations at (Ku, Ka). $N_{\text {accurate }}$ is the proportion (in \%) of the 25589 collocated APR samples that are accurately approximated by at least one of the T-matrix simulations.

\begin{tabular}{|c|c|c|c|c|c|c|c|c|c|}
\hline \multirow{2}{*}{$\begin{array}{c}\text { MSP } \\
\text { set }\end{array}$} & \multirow{2}{*}{$\begin{array}{c}\text { Radar } \\
\text { frequencies }\end{array}$} & \multirow{2}{*}{$\begin{array}{c}N_{\text {accurate }} \\
(\%)\end{array}$} & \multicolumn{3}{|c|}{$\begin{array}{c}\text { Correlation } C \\
(\%)\end{array}$} & \multicolumn{3}{|c|}{$\begin{array}{c}\text { Bias } B \\
(\%) \\
\end{array}$} & \multirow[b]{2}{*}{ OMSP diagonal } \\
\hline & & & $\bar{M}$ & $D_{m}$ & $S_{m}$ & $M$ & $D_{m}$ & $S_{m}$ & \\
\hline $\mathrm{AfBf}$ & $\mathrm{Ku}, \mathrm{Ka}$ & 60 & \multicolumn{6}{|c|}{ Baseline for calculation of $C$ and $B$} & $b \sim 0.133 a_{\mathrm{dB}}+5.030$ \\
\hline $\mathrm{AcBc}$ & $\mathrm{Ku}, \mathrm{Ka}$ & 31 & 95 & 97 & 91 & -8 & 3 & -1 & $b \sim 0.115 a_{\mathrm{dB}}+4.804$ \\
\hline $\mathrm{AuBf}$ & $\mathrm{Ku}, \mathrm{Ka}$ & 27 & 96 & 97 & 95 & 8 & -4 & 2 & $b=1.67$ most frequent $(\sim 60 \%$ of cases $)$ \\
\hline $\mathrm{AfBu}$ & $\mathrm{Ku}, \mathrm{Ka}$ & 22 & 95 & 97 & 89 & 17 & -11 & 5 & $a=0.0037 \mathrm{~g} \mathrm{~cm}^{-1.67}$ most frequent ( $\sim 75 \%$ of cases) \\
\hline $\mathrm{AuBu}$ & $\mathrm{Ku}, \mathrm{Ka}$ & 18 & 94 & 96 & 78 & 20 & -11 & 1 & No MSP variation $\left(a=0.0037 \mathrm{~g} \mathrm{~cm}^{-1.67}, b=1.67\right)$ \\
\hline $\mathrm{AmBu}$ & $\mathrm{Ku}, \mathrm{Ka}$ & 3 & 93 & 97 & 94 & 28 & -6 & 6 & No MSP variation $\left(a=0.0019 \mathrm{~g} \mathrm{~cm}^{-1.67}, b=1.67\right)$ \\
\hline $\mathrm{ApBu}$ & $\mathrm{Ku}, \mathrm{Ka}$ & 2 & 84 & 80 & 77 & -30 & -30 & 16 & No MSP variation $\left(a=0.0071 \mathrm{~g} \mathrm{~cm}^{-1.67}, b=1.67\right)$ \\
\hline $\mathrm{AuBm}$ & $\mathrm{Ku}, \mathrm{Ka}$ & 3 & 86 & 81 & 70 & -28 & -14 & 10 & No MSP variation $\left(a=0.0037 \mathrm{~g} \mathrm{~cm}^{-1.34}, b=1.34\right)$ \\
\hline $\mathrm{AuBp}$ & $\mathrm{Ku}, \mathrm{Ka}$ & 6 & 94 & 95 & 93 & 8 & 10 & 1 & No MSP variation $\left(a=0.0037 \mathrm{~g} \mathrm{~cm}^{-2}, b=2\right)$ \\
\hline
\end{tabular}

reference $D_{0}$ has a similar behavior as the retrievals, one can note the limited range of the Nevzorov measurements for $Z_{A, \mathrm{Ku}} \geq 22 \mathrm{~dB} Z\left(Z_{A, \mathrm{Ku}} \leq 5 \mathrm{~dB} Z\right)$, where $M_{\mathrm{Nev}}$ underestimates (overestimates) the IWC. There are some differences between the reflectivities measured during the two campaigns: specific to GCPEx are the small particles for $Z_{\mathrm{Ku}} \leq-5 \mathrm{~dB} Z$ and larger particles for $\left(Z_{\mathrm{Ku}} \geq 15 \mathrm{~dB} Z, Z_{\mathrm{Ku}-\mathrm{Ka}} \geq 10 \mathrm{~dB}\right)$; on the other hand, in OLYMPEx, there are heavier particles for $\left(Z_{\mathrm{Ku}} \geq\right.$ $\left.25 \mathrm{~dB} Z, Z_{\mathrm{Ku}-\mathrm{Ka}} \leq 4 \mathrm{~dB}\right)$. All these differences explain the intercampaign differences in Fig. 5a: in general, the exponents $b$ of the OMSPs of GCPEx are larger than those of OLYMPEx (blue line above red line). Figure 5c confirms the correlation between GCPEx and OLYMPEx retrievals of $M$ and $D_{m}$, and the lower correlation between retrieved $S_{m}$, consistent with the D3R dashboard (Fig. 4). The median of the profiles where GCPEx and OLYMPEx retrievals agree are plotted in Fig. 5d as a function of altitude (left) and temperature (right). These graphs confirm the high resemblance between the APR profiles of GCPEx and OLYMPEx (especially at Ku band), particularly in the representation as a function of the temperature.

\section{Sensitivity of the OMSPs and microphysical retrievals}

This section discusses the sensitivity of the OMSP retrievals, following the approach of Pianosi et al. (2016): the sensitivity to the input parameters is analyzed globally in section $6 \mathrm{a}$ [by varying the quantization of the space of $(a, b)$ parameters] and locally in section 6b [by perturbing $(a, b)$ around a fixed value]. Section $6 c$ analyzes the sensitivity to the scattering model. For the sake of simplicity, the remainder of the article focuses on OLYMPEx in situ observations and collocated APR measurements. Although not shown, similar results are obtained with GCPEx or D3R data.

\section{a. Sensitivity to the quantization of the space of mass-size parameters}

Five sets of MSP parameterizations are studied to assess how sensitive the retrievals are to the quantization of the MSP space [set of values for $a$ and $b$ in $\left.m(D)=a D^{b}\right]$ :

- "AfBf" (fine sampling of $a$ and $b$ ): It is the full set of power laws used so far (baseline); as described in section $3 \mathrm{~b}$, it consists of eight values for $a$ and seven values for $b$;

- "AcBc" (coarse sampling of $a$ and $b$ ): This set retains every other prefactor and exponent of AfBf $\left[a_{1}=0.0005\right.$,

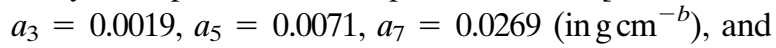
$b_{1}=1.01, b_{3}=1.67, b_{5}=2.34$, and $b_{7}=3$ ];

- "AuBf" (unique $a=0.0037 \mathrm{~g} \mathrm{~cm}^{-b}$, fine sampling of $b$ ): Only varying the exponent $b$;

- "AfBu" (fine sampling of $a$, unique $b=1.67$ ): Only varying the prefactor $a$;

- "AuBu" $\left(a=0.0037 \mathrm{~g} \mathrm{~cm}^{-1.67}\right.$ and $\left.b=1.67\right)$ : Not allowing for any MSP variation.

The retrievals are compared on a dashboard, where the AfBf configuration is the baseline. Table 3 summarizes the results through the number of collocated APR observations accurately approximated by the chosen MSP set, the correlation coefficient $C$ and relative bias $B$ of the bulk moments $\left(M, D_{m}, S_{m}\right)$, and the equation of the OMSP "diagonal."

All the retrieved moments are strongly correlated to those of AfBf: even in the AuBu case, where the MSP is kept fixed, $C$ is higher than $78 \%$. The main difference is in the number of collocated records that are accurately 
approximated by the simulations: the coarser the set of MSPs, the smaller the number of accurate approximations of reflectivities (from $60 \%$ with AfBf to less than $20 \%$ for the AuBu case). The variability of the exponent $b$ seems to have a stronger impact on the range of accuracy of the simulated reflectivities, since AuBf approximates accurately more collocated records than $\mathrm{AfBu}$, and the retrievals from $\mathrm{AuBf}$ have smaller biases than the retrievals from AfBu.

The equations of the OMSP "diagonals" of AfBf and $\mathrm{AcBc}$ are different due to the quantization. In the univariate cases, the MSPs that have the highest frequency of occurrence are close to the AfBf diagonal (defined by $b_{\mathrm{AfBf}}=0.133 a_{\mathrm{dB}}+5.030$ ): in the AuBf case (i.e., $a=$ $\left.a_{\mathrm{AuBf}}=0.0037 \mathrm{~g} \mathrm{~cm}^{-b}\right), b_{\mathrm{AuBf}}=1.67$ is the exponent with the highest frequency of occurrence $(\sim 60 \%)$, which is close to the corresponding value on the diagonal $b_{\mathrm{AfBf}}\left(a_{\mathrm{AuBf}}\right)=1.80$; on the other hand, in the AfBu case (i.e., $\left.b=b_{\mathrm{AfBu}}=1.67\right), a_{\mathrm{AfBu}}=0.0037 \mathrm{~g} \mathrm{~cm}^{-1.67}$ is the prefactor with the highest frequency of occurrence $(\sim 75 \%)$, which is close to the corresponding value on the diagonal $a_{\mathrm{AfBu}}\left(b_{\mathrm{AfBu}}\right)=0.0030 \mathrm{~g} \mathrm{~cm}^{-1.67}$. All these similarities show that the optimization converges to OMSPs that have characteristics similar to those of AfBf.

\section{b. Local sensitivity to the mass-size parameters}

We now study the effect of local perturbations of the MSP parameters around $\mathrm{AuBu}$, which has fixed $a=0.0037 \mathrm{~g} \mathrm{~cm}^{-1.67}$ and $b=1.67$. The four fixed MSPs considered are

- "AmBu": $a=0.0019 \mathrm{~g} \mathrm{~cm}^{-1.67}$ and $b=1.67$;

- "ApBu": $a=0.0071 \mathrm{~g} \mathrm{~cm}^{-1.67}$ and $b=1.67$;

- "AuBm": $a=0.0037 \mathrm{~g} \mathrm{~cm}^{-1.34}$ and $b=1.34$;

- “AuBp": $a=0.0037 \mathrm{~g} \mathrm{~cm}^{-2}$ and $b=2$.

The results of comparisons to the AfBf configuration (baseline) are provided in Table 3 (bottom rows). The retrieved moments still have high correlations to those of AfBf (higher than 72\%); however, there are clear differences with respect to the performance of $\mathrm{AuBu}$ both in terms of the number of accurately approximated records (all smaller than $6 \%$ of the total), and in terms of bias (except for AuBp, which has small biases). Thus, the choice of the MSP coefficients has a significant impact on the ability to approximate radar observations.

\section{c. Sensitivity to the scattering model}

So far, a T-matrix code was used to compute the radar reflectivities according to Eq. (1). In this framework (denoted " $\mathrm{TM}_{\mathrm{in}}$ "), the scatterers are modeled as oblate spheroids of maximum size $D$ and aspect ratio $R_{\mathrm{ASP}}(D)$ derived from the imaging probes. The approach is now extended to include Mie and discrete-dipole approximation (DDA) scattering models. The Mie calculations, correspond to T-matrix calculations where scatterers are modeled as spheres of diameter $D$. The Mie reflectivities are therefore computed using $\mathrm{TM}_{\text {in }}$ with a fixed aspect ratio of 1 . The DDA model computes the scattering properties of irregularly shaped scatterers by dividing them into dipoles (Purcell and Pennypacker 1973). The DDA is therefore conformal to the geometry of irregularly shaped particles. For the DDA calculations, we use the OpenSSP lookup table (LUT) built using the DDSCAT software (Draine and Flatau 1994; Kuo et al. 2016). OpenSSP (available online at https:// storm.pps.eosdis.nasa.gov/storm/OpenSSP.jsp) consists of 9053 ice particles of varying shapes (from pristine ice to aggregates) and sizes $(D \in[0.15,17.27] \mathrm{mm})$. To compute the backscattering cross sections, we read OpenSSP using $D$ and the mass $m(D)$ assumed by the simulated MSP and average over all the habits in the LUT. With the three scattering models $\left(\mathrm{Mie}, \mathrm{TM}_{\mathrm{in}}\right.$ and DDA) and the PSDs measured during OLYMPEx, reflectivity factors are computed at $\mathrm{Ku}$ and $\mathrm{Ka}$ bands, for all the MSPs. Collocated (Ku, Ka)-band observations from APR then allow us to identify the OMSPs. Although the same in situ and radar data are used in these simulations, the intrinsic assumptions of the three scattering models are different, and therefore, the models will produce radar reflectivities that are not identical. Thus, the OMSPs of the various scattering models will not be identical (the MSPs such that $\Delta_{\mathrm{Ku}, \mathrm{Ka}} \leq 1.5 \mathrm{~dB}$ may vary from one model to the other).

The retrieval dashboard is shown in Fig. 6. Of 25589 collocated APR samples (this number corresponds to collocated samples such that $T \leq-1^{\circ} \mathrm{C}$, with low liquid PIA and LWC), the Mie approach accurately approximates $51 \%$ of the samples, whereas $\mathrm{TM}_{\mathrm{in}}$ and DDA both accurately approximate $\sim 60 \%$ of the samples ( $\sim 2000$ more samples than Mie). There are therefore advantages in using scattering models that account for the morphological diversity of frozen hydrometeors.

The three models produce very similar preferential MSPs (Fig. 6a). The OMSP diagonals are slightly different between DDA (higher $b$ ) and Mie (lower $b$ ), with $\mathrm{TM}_{\mathrm{in}}$ bracketed by these two models: the $\mathrm{TM}_{\text {in }}$ diagonal transitions from being similar to the Mie diagonal for lower $a$ and $b$ to being closer to the DDA diagonal for larger $a$ and $b$. Figure 6b shows the bulk moments (reference in top row, retrievals below) as a function of the collocated APR observations $\left(Z_{\mathrm{Ku}}, Z_{\mathrm{Ku}-\mathrm{Ka}}\right)$, for simulations done using $\mathrm{TM}_{\text {in }}$ (top two rows), DDA (third row), and Mie (bottom row). Figure $6 \mathrm{~b}$ confirms the 

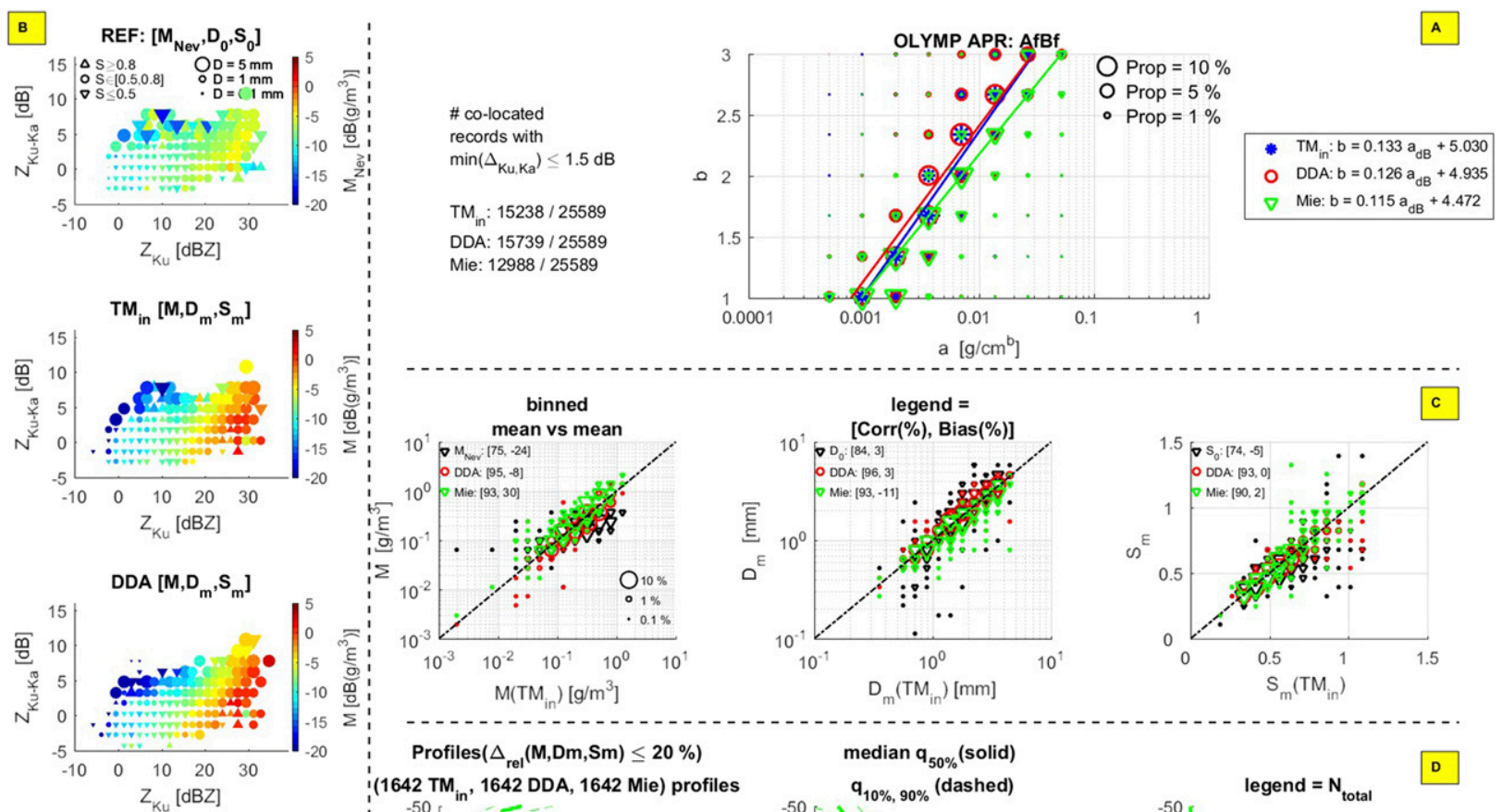

\begin{tabular}{c:c}
$\operatorname{Profiles}\left(\Delta_{\text {rel }}(\mathrm{M}, \mathrm{Dm}, \mathrm{Sm}) \leq 20 \%\right)$ \\
\hdashline$\left(1642 \mathrm{TM}_{\mathrm{in}}, 1642 \mathrm{DDA}, 1642 \mathrm{Mie}\right)$ profiles
\end{tabular}
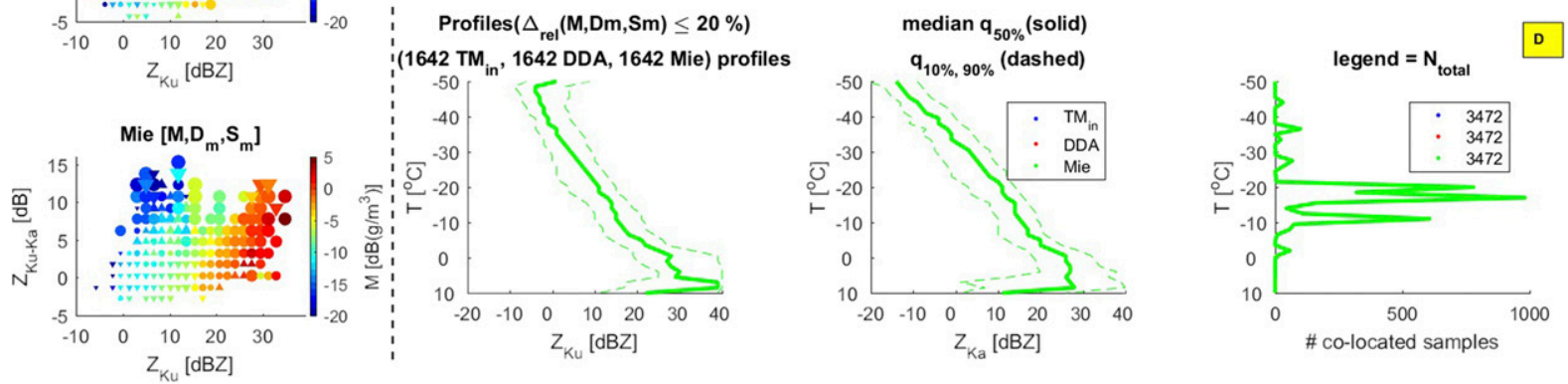

FIG. 6. Sensitivity of retrievals to the scattering models (T matrix vs DDA vs Mie), with simulations constrained by APR (Ku, Ka) data from OLYMPEx: (a) Distribution of OMSPs as a function of $(a, b)$ (marker size represents the occurrence frequency, and solid line is OMSP "diagonal"). (b) Mean values of bulk moments [(top) references, (bottom three rows) retrievals], conditional to ( $\left.Z_{\mathrm{Ku}}, Z_{\mathrm{Ku}-\mathrm{Ka}}\right)$ measured by APR in OLYMPEx, based on scattering simulations from (top two rows) $\mathrm{TM}_{\mathrm{in}}$, (third row) DDA, and (bottom) Mie: IWC (marker color), mean diameter (marker size), and spread (marker type). (c) Scatterplots comparing bulk moments retrieved from $\mathrm{TM}_{\mathrm{in}}$ (horizontal axis) to those from DDA and Mie and references (vertical axis, marker size represents occurrence frequency). (d) Profiles where retrievals from $\mathrm{TM}_{\mathrm{in}}$, DDA and Mie agree within $20 \%$ of relative error: vertical profiles of quantiles of (left) $Z_{\mathrm{Ku}}$ and (center) $Z_{\mathrm{Ka}}$, and (right) number of samples.

features seen in the previous dashboards, namely, 1) the saturation of $M_{\mathrm{Nev}}$ for lower and larger IWCs, 2) a joint dependency of $M$ on $\left.\left(Z_{\mathrm{Ku}}, Z_{\mathrm{Ku}-\mathrm{Ka}}\right), 3\right)$ increasing $D_{m}$ with increasing $Z_{\mathrm{Ku}-\mathrm{Ka}}$, and 4) larger spreads $S_{m}$ for larger $Z_{\mathrm{Ku}}$. Among the slight intermodel differences, one can note the presence, only in the Mie results, of samples for $\left(Z_{\mathrm{Ku}}<10 \mathrm{~dB} Z, Z_{\mathrm{Ku}-\mathrm{Ka}} \geq 8 \mathrm{~dB}\right)$, which correspond to larger particles with a low mass and narrow spread. Figure $6 \mathrm{c}$ shows a very strong correlation between the retrieved moments. However, there are also nonnegligible biases between Mie results and the results from the other scattering models: to match a given radar observation simulated by $\mathrm{TM}_{\text {in }}$ or DDA (a bin in the $\left(Z_{\mathrm{Ku}}, Z_{\mathrm{Ku}-\mathrm{Ka}}, T\right)$-hypercube), the Mie approach uses smaller $\left(D_{m}\right.$ smaller by $\left.-10 \%\right)$ but heavier $(M$ larger by $+31 \%)$ spheres than the particles used in $\mathrm{TM}_{\mathrm{in}}$ and DDA. Figure $6 \mathrm{~d}$ shows that the closest agreements between the three scattering models are observed at temperatures colder than $-10^{\circ} \mathrm{C}$.

\section{Conclusions}

This article has illustrated the high value of multiinstrumented field campaigns such as GCPEx and OLYMPEx to observe frozen hydrometeors, model their scattering behavior, and estimate their microphysical properties. By measuring the thermodynamic characteristics of the atmosphere, such field campaigns provide a depiction of the true state of the atmosphere, which can be used as a reference to develop radar retrieval algorithms. 
The presented work has shown that in situ measurements of microphysical properties of ice and snow (particle sizes and aspect ratios) could be related to collocated observations from airborne and ground-based radars, even when the true mass-size characteristics of the scatterers are unknown (measured neither during GCPEx nor OLYMPEx). Our approach consists in parameterizing the mass-size dependency of scatterers via a large ensemble of power laws, and using various scattering simulators (T matrix, Mie, DDSCAT) to compute unattenuated radar reflectivity factors. Properly collocated and screened radar observations then allowed us to identify the optimal parameterizations, or OMSPs. We introduced a "retrieval dashboard" to jointly analyze the OMSPs and the relationship between the retrieved microphysical moments $\left(M, D_{m}, S_{m}\right)$, the local thermodynamics and remote sensing observations. The dashboard, through its conditioning hypercube, provides a means for quantitative comparisons between retrievals from various instruments (APR vs D3R) or campaigns (GCPEx vs OLYMPEx).

In this framework, all the results obtained confirm that the MSP is the factor that causes the highest variability in multifrequency radar simulations. The OMSPs depend on the magnitude of the radar responses and on the scattering model used to simulate the radar observations. A sensitivity analysis showed the advantage of using 1) morphologically agile scattering models such the DDA or T matrix with the measured aspect ratio, and 2) a refined set of mass-size relationships. This article illustrates also the difficulty to find a "universal" parameterization that fits all radar observations. However, the preferential OMSPs tend to cluster along a "diagonal" band of the $(a, b)$ plane. These results confirm findings previously reported in the literature (Heymsfield et al. 2002a; Finlon et al. 2019).

The instances of triple-collocation APR-CIT-D3R in GCPEx and OLYMPEx showed the insensitivity of the retrievals to the observing platform: similar retrievals are obtained whether based on APR or D3R observations, which indicates also a decent cross calibration between the two radars.

The dashboard provided a common platform to compare retrievals from all the airborne (or ground based) radar data collected in GCPEx to those from OLYMPEx. Despite the differences in intensities of the sampled events (more intense precipitation in OLYMPEx), the comparisons have shown a good agreement between retrievals of $M$ and $D_{m}$, whereas the retrieval of $S_{m}$ seems campaign dependent. For this type of comparison between different meteorological regimes, a representation of the radar data as a function of the temperature (CFTD format) is more suitable than a representation as a function of altitude (CFAD format) to highlight common features between radar profiles. Such similarities hint at common properties in the thermodynamic processes that take place in the entire radar profile, that is, beyond the location of the radar/in situ collocation.

Most of the work presented in this article is based on dual-frequency $(\mathrm{Ku}, \mathrm{Ka})$ radar observations and simulations. However, the approach followed can be applied to other combinations of frequencies or other remote sensing observations. Our retrieval approach does not attempt to build an explicit analytical retrieval operator, but instead it provides a distribution of values of the retrieved $\left(M, D_{m}, S_{m}\right)$. In the same vein, big-data methods (e.g., machine learning) could be envisioned to better characterize the microphysics of hydrometeors using radars.

Acknowledgments. The authors would like to thank the editor and reviewers for their constructive remarks. The research described in this article was carried out at the Jet Propulsion Laboratory, California Institute of Technology, under a contract with the National Aeronautics and Space Administration. Government sponsorship is acknowledged. Support from the NASA Precipitation Measurement Missions program and the GPM Ground Validation program are gratefully acknowledged. Dr. Heymsfield and Dr. Bansemer gratefully acknowledge the support from GPM, CloudSat and JAXA. The authors would like to acknowledge Dr. Joe Turk, Manuel "Marty" Martinez and Prof. Pavlos Kollias for fruitful discussions during the preparation of this article.

\section{APPENDIX A}

\section{Screening of Liquid Attenuation}

Liquid or mixed-phase scatterers can strongly attenuate radar observations especially at higher frequencies. This is a problem for the MSP analysis, as it relies on comparisons between radar measurements and simulations of unattenuated radar reflectivities. Frozen hydrometeors also attenuate the radar signal. However, in the absence of high-density hydrometeors (e.g., hail and graupel), as is the case in GCPEx and OLYMPEx, the attenuation at $\mathrm{Ku}$ and $\mathrm{Ka}$ bands by low-density snow/ice is not as strong as the liquid attenuation. Moreover, for frozen particles, the extinction coefficient depends on the masses of the particles, which are unknown and the objective of this article. In addition, attenuation corrections, for example, using the Hitschfeld-Bordan approach, are 
delicate since they solve for a mathematically illposed problem (Hitschfeld and Bordan 1954).

To avoid biasing the results of our analysis, we focus on the attenuation by liquid particles and try to identify and eliminate the radar observations that are severely attenuated. For every collocated sample, the two-way PIA due to liquids is computed between the location of the radar and the CIT as

$$
\operatorname{PIA}_{f}\left(r_{\mathrm{CIT}}\right)=2 \int_{0}^{r_{\mathrm{CIT}}} k_{\mathrm{ext}, f}(s) d s,
$$

with $f$ the radar frequency, and $r_{\mathrm{CIT}}$ the line-of-sight distance between the radar and the CIT. The extinction coefficient $k_{\text {ext }, f}$ (in $\mathrm{dB} \mathrm{km}^{-1}$ ) is deduced from the reflectivity $Z_{\mathrm{Ku}}$ at $\mathrm{Ku}$ band (in $\mathrm{mm}^{6} \mathrm{~m}^{-3}$ ), by assuming that $Z_{\mathrm{Ku}}$ is marginally attenuated. This is done using the relationship

$$
k_{\mathrm{ext}, f}=\alpha_{\mathrm{Ku} \rightarrow f}\left(Z_{\mathrm{Ku}}\right)^{\beta_{\mathrm{Ku} \rightarrow f}} .
$$

The coefficients $\left(\alpha_{\mathrm{Ku} \rightarrow f}, \beta_{\mathrm{Ku} \rightarrow f}\right)$, which are listed in Table A1, are obtained from T-matrix simulations $\left(\mathrm{TM}_{\mathrm{in}}\right)$ using all the PSDs measured during GCPEx and OLYMPEx, at temperatures $T \geq 1{ }^{\circ} \mathrm{C}$.

In cases where $\mathrm{Ku}$-band data are unavailable (due to the limited sensitivity of $\mathrm{Ku}$ in APR compared to Ka band), the $k-Z$ relationships used are between $k_{\text {ext,Ka }}$ and $Z_{\mathrm{Ka}}$, the reflectivity at Ka band (parameters listed in Table A1). The computed PIAs allow to flag the collocated samples where the liquid attenuation exceeds the threshold PIA max $=0.5 \mathrm{~dB}$.

\section{APPENDIX B}

\section{References for the Retrieved Bulk Moments}

The retrieved moments are the bulk moments $\left(M, D_{m}, S_{m}\right)$ of the OMSPs. The true values of these bulk moments all require knowledge of the true $m(D)$ relationship, which is was measured neither during GCPEx nor OLYMPEx. Instead, reference values are sought to provide an indication of the magnitudes of the bulk moments. This appendix discusses the references for the various bulk moments, which are illustrated using data from OLYMPEx (similar results are obtained with GCPEx). The OMSPs are determined by constraining T-matrix simulations via collocated APR observations at $\mathrm{Ku}$ and $\mathrm{Ka}$ bands.

The reference chosen for $M$ is the total water content $M_{\mathrm{Nev}}$ measured by the Nevzorov probe at negative temperatures. Even though $M_{\mathrm{Nev}}$ can occasionally underestimate the true water content (see, e.g., Korolev
TABLE A1. Parameters of $k-Z$ relationships from in situ measurements at temperatures $T \geq 1^{\circ} \mathrm{C}$ during GCPEx and OLYMPEx. Scattering calculations from $\mathrm{T}$ matrix $\left(\mathrm{TM}_{\mathrm{in}}\right)$. In the relationship $k_{\text {ext }, f_{2}}=\alpha_{f_{1} \rightarrow f_{2}}\left(Z_{f_{1}}\right)^{\beta_{f_{1}} \rightarrow f_{2}}, Z_{f_{1}}$ is the reflectivity at frequency $f_{1}$ in $\mathrm{mm}^{6} \mathrm{~m}^{-3}, k_{\mathrm{ext}, f_{2}}$ is the desired extinction at frequency $f_{2}$ in $\mathrm{dB} \mathrm{km}^{-1}, \alpha_{f_{1} \rightarrow f_{2}}$ is in $\mathrm{dB} \mathrm{km}^{-1}\left(\mathrm{~mm}^{6} \mathrm{~m}^{-3}\right)^{-1}$, and $\beta_{f_{1} \rightarrow f_{2}}$ is

\begin{tabular}{|c|c|c|c|c|c|}
\hline \multicolumn{2}{|c|}{ Frequency } & \multicolumn{2}{|c|}{ GCPEx } & \multicolumn{2}{|c|}{ OLYMPEx } \\
\hline$Z_{f_{1}}$ & $k_{\mathrm{ext}, f_{2}}$ & $\alpha_{f_{1} \rightarrow f_{2}}$ & $\beta_{f_{1} \rightarrow f_{2}}$ & $\alpha_{f_{1} \rightarrow f_{2}}$ & $\beta_{f_{1} \rightarrow f_{2}}$ \\
\hline $\mathrm{Ku}$ & $\mathrm{Ku}$ & $1.532 \times 10^{-4}$ & 0.72 & $1.606 \times 10^{-4}$ & 0.72 \\
\hline $\mathrm{Ka}$ & $\mathrm{Ka}$ & $5.335 \times 10^{-4}$ & 0.92 & $6.685 \times 10^{-4}$ & 0.91 \\
\hline $\mathrm{Ku}$ & $\mathrm{Ka}$ & $9.966 \times 10^{-3}$ & 0.43 & $1.103 \times 10^{-2}$ & 0.43 \\
\hline
\end{tabular}
unitless.

et al. 2013), it is the only available independent measurement of ice water content (for $M_{\mathrm{Nev}} \in[0.02$, 1.5] $\mathrm{g} \mathrm{m}^{-3}$ ). For $D_{m}$ and $S_{m}$, one option could be to use the $P S D$-weighted mean $D_{N}=\mathbb{E}_{N}(D)$ and spread $S_{N}=\sqrt{\mathbb{E}_{N}\left[\left(D-D_{N}\right)^{2}\right] / D_{N}}$, with $\mathbb{E}_{N}(\cdot)$ defined as

$$
\begin{aligned}
\mathbb{E}_{N}(y)= & \frac{1}{N_{T}} \int_{D_{\min }}^{D_{\max }} y(D) N(D) d D, \\
& \text { for any function } y(D), \\
N_{T}= & \int_{D_{\min }}^{D_{\max }} N(D) d D
\end{aligned}
$$

However, in this case, the kernel $N(D)$ is quite different than the kernel $m(D) N(D)$ used to define $D_{m}$ and $S_{m}$ [see Eqs. (3) and (4)]. Figure 7 displays scatterplots of the retrieved moments ( $M$ in top row, $D_{m}$ in middle row, $S_{m}$ in bottom row) as a function of the references (blue asterisks). The plots in the left column correspond to unconstrained simulations (all MSPs equally likely), whereas the plots in the right column correspond to the OMSPs. The MSP perturbation leads to a large variability of the moments, especially for $M$. The MSP optimization reduces this variability significantly (top right), leading to a stronger correlation between $M$ and $M_{\text {Nev }}$. However, the retrieved $M$ are also biased positively compared to $M_{\mathrm{Nev}}$, most likely due to the saturation of the Nevzorov probe. The histograms of $D_{m}$ versus $D_{N}$ and $S_{m}$ versus $S_{N}$ (blue asterisks in bottom two rows) show large dispersions, which are not reduced by the MSP optimization. Thus $\left(D_{N}, S_{N}\right)$ are not suitable references for mass-weighted moments such as $\left(D_{m}, S_{m}\right)$.

As an alternative, volume-weighted statistics can be considered through the mean $D_{V}=\mathbb{E}_{V}(D)$ and the spread $S_{V}=\sqrt{\mathbb{E}_{V}\left[\left(D-D_{V}\right)^{2}\right]} / D_{V}$, where the expectation $\mathbb{E}_{V}(\cdot)$ is defined in Eq. (10). These moments are defined by a kernel that is the product between $N(D)$ and an increasing function of $D$ [the volume $v(D)$ ], similar to $m(D) N(D)$ used to define $\left(M, D_{m}, S_{m}\right)$. Figure 7 (green 

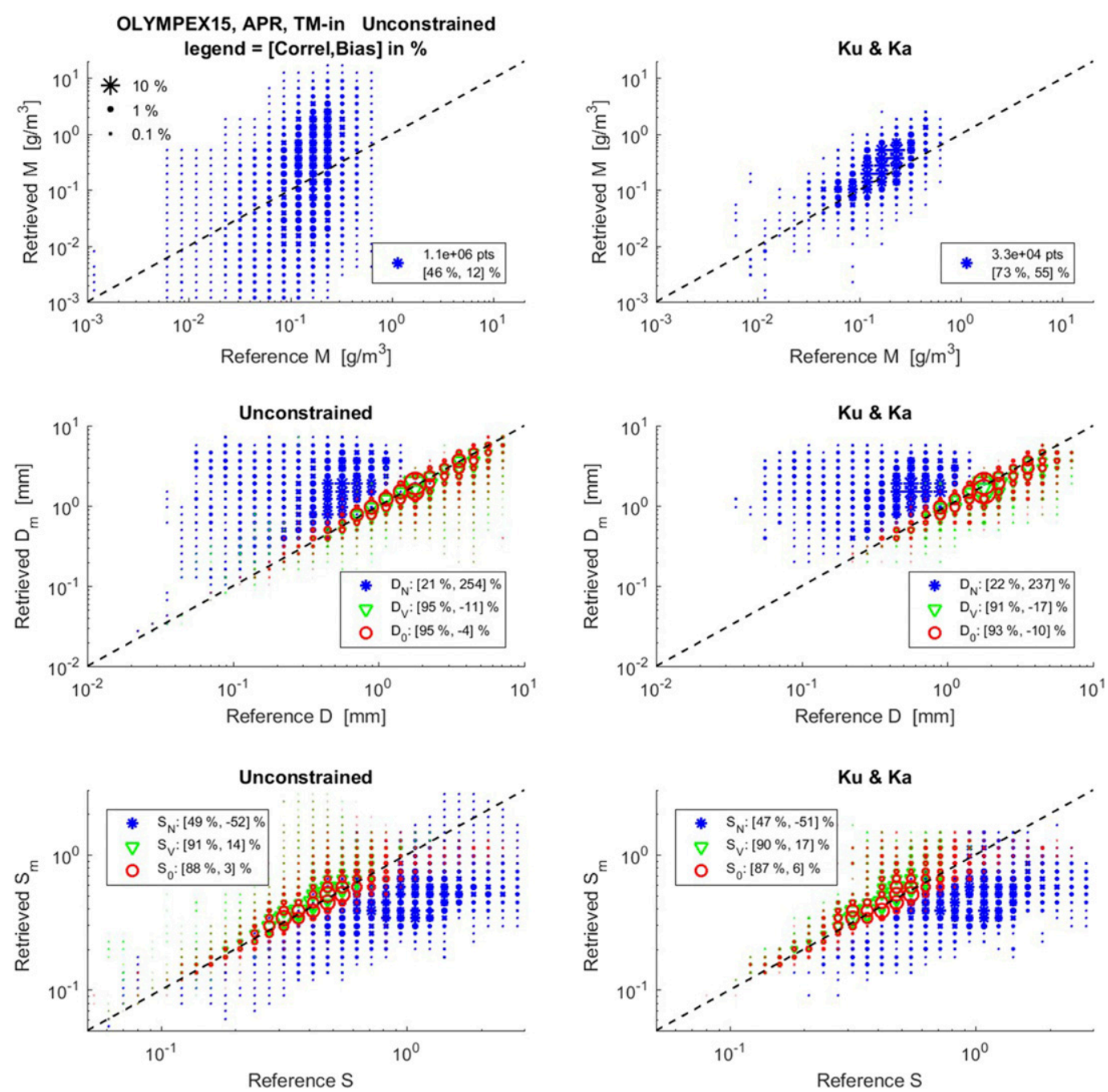

FIG. 7. Choice of references for retrieved bulk moments: scatterplots of (top) retrieved $M$ vs $M_{\mathrm{Nev}}$ measured by Nevzorov probe; (middle) retrieved $D_{m}$ vs mean PSD-weighted diameter $D_{N}$, volume-weighted diameter $D_{v}$, and median-volume diameter $D_{0}$; and (bottom) retrieved $S_{m}$ vs normalized spreads $S_{N}$ (PSD-weighted about $D_{N}$ ), $S_{V}$ (volume weighted about $D_{V}$ ), and $S_{0}$ (volume weighted about $D_{0}$ ). (left) (Unconstrained), all the MSPs are shown since no collocated radar observation is used. (right) APR observations at $(\mathrm{Ku}, \mathrm{Ka})$ are used to constrain $\mathrm{TM}_{\text {in }}$ simulations. The error statistics in the legend are the correlation coefficient $C$ and relative bias $B$, both in $\%$.

markers in second and third rows) shows the strong correlation between $D_{m}$ and $D_{V}$, and similarly between $S_{m}$ and $S_{V}$, even in the unconstrained case. However, there are also biases between retrieved and reference quantities $\left(D_{m}\right.$ smaller than $D_{V}$, and $S_{m}$ larger than $\left.S_{V}\right)$, due to the fact that $v(D)$ is not $m(D)$. To avoid such biases, we choose as references the median-volume diameter $D_{0}$ [defined by Eq. (8)], and the volume-weighted spread about $D_{0}$, that is, $S_{0}=\sqrt{\mathbb{E}_{V}\left[\left(D-D_{0}\right)^{2}\right]} / D_{0}$. Figure 7 (red markers in middle and bottom rows) shows the strong correlations between $\left(D_{m}, S_{m}\right)$ and $\left(D_{0}, S_{0}\right)$, as well as the reduced biases compared to those of $\left(D_{V}, S_{V}\right)$.

\section{REFERENCES}

Brandes, E. A., G. Zhang, and J. Vivekanandan, 2004: Drop size distribution retrieval with polarimetric radar: Model and application. J. Appl. Meteor., 43, 461-475, https://doi.org/10.1175/ 1520-0450(2004)043<0461:DSDRWP>2.0.CO;2.

Bruggeman, D. A. G., 1935: Berechnung verschiedener physikalischer Konstanten von heterogenen Substanzen. I. Dielektrizitätskonstanten und Leitfähigkeiten der Mischkörper aus isotropen Substanzen. Ann. Phys., 416, 636-664, https:// doi.org/10.1002/andp.19354160705.

Chase, R. J., and Coauthors, 2018: Evaluation of triplefrequency radar retrieval of snowfall properties using coincident airborne in situ observations during OLYMPEX. Geophys. Res. Lett., 45, 5752-5760, https://doi.org/10.1029/ 2018 GL077997. 
Doviak, R. J., and D. S. Zrnić, 1993: Doppler Radar and Weather Observations. 2nd ed. Academic Press, 562 pp.

Draine, B. T., and P. J. Flatau, 1994: Discrete-dipole approximation for scattering calculations. J. Opt. Soc. Amer., 11A, 14911499, https://doi.org/10.1364/JOSAA.11.001491.

Durden, S. L., S. Tanelli, and O. O. Sy, 2020: Comparison of GPM DPR and airborne radar observations in OLYMPEX. IEEE Geosci. Remote Sens. Lett., https://doi.org/10.1109/ LGRS.2019.2952287, in press.

Falconi, M. T., A. von Lerber, D. Ori, F. S. Marzano, and D. Moisseev, 2018: Snowfall retrieval at X, Ka and W bands: Consistency of backscattering and microphysical properties using BAECC ground-based measurements. Atmos. Meas. Tech., 11, 3059-3079, https://doi.org/10.5194/amt-11-30592018.

Field, P. R., A. J. Heymsfield, and A. Bansemer, 2006: Shattering and particle interarrival times measured by optical array probes in ice clouds. J. Atmos. Oceanic Technol., 23, 13571371, https://doi.org/10.1175/JTECH1922.1.

Finlon, J. A., G. M. McFarquhar, S. W. Nesbitt, R. M. Rauber, H. Morrison, W. Wu, and P. Zhang, 2019: A novel approach for characterizing the variability in mass-dimension relationships: Results from MC3E. Atmos. Chem. Phys., 19, 36213643, https://doi.org/10.5194/acp-19-3621-2019.

Fontaine, E., A. Schwarzenboeck, J. Delanoë, W. Wobrock, D. Leroy, R. Dupuy, C. Gourbeyre, and A. Protat, 2014: Constraining mass-diameter relations from hydrometeor images and cloud radar reflectivities in tropical continental and oceanic convective anvils. Atmos. Chem. Phys., 14, 11367 11392, https://doi.org/10.5194/acp-14-11367-2014.

Grecu, M., L. Tian, W. S. Olson, and S. Tanelli, 2011: A robust dualfrequency radar profiling algorithm. J. Appl. Meteor. Climatol., 50, 1543-1557, https://doi.org/10.1175/2011JAMC2655.1.

Haddad, Z. S., R. C. Sawaya, S. Kacimi, O. O. Sy, F. J. Turk, and J. Steward, 2017: Interpreting millimeter-wave radiances over tropical convective clouds. J. Geophys. Res. Atmos., 122, 1650 1664, https://doi.org/10.1002/2016JD025923.

Heymsfield, A. J., and J. L. Parrish, 1978: A computational technique for increasing the effective sampling volume of the PMS two-dimensional particle size spectrometer. J. Appl. Meteor., 17, 1566-1572, https://doi.org/10.1175/1520-0450(1978)017\% 3C1566:ACTFIT\%3E2.0.CO;2.

— A. Bansemer, P. R. Field, S. L. Durden, J. L. Stith, J. E. Dye, W. Hall, and C. A. Grainger, 2002a: Observations and parameterizations of particle size distributions in deep tropical cirrus and stratiform precipitating clouds: Results from in situ observations in TRMM field campaigns. J. Atmos. Sci., 59, 3457-3491, https://doi.org/10.1175/1520-0469(2002)059<3457: OAPOPS $>2.0 . \mathrm{CO} ; 2$.

— S. Lewis, A. Bansemer, J. Iaquinta, L. M. Miloshevich, M. Kajikawa, C. Twohy, and M. R. Poellot, 2002b: A general approach for deriving the properties of cirrus and stratiform ice cloud particles. J. Atmos. Sci., 59, 3-29, https://doi.org/ 10.1175/1520-0469(2002)059<0003:AGAFDT>2.0.CO;2.

—, A. Bansemer, N. B. Wood, G. Liu, S. Tanelli, O. O. Sy, M. Poellot, and C. Liu, 2018: Toward improving ice water content and snow-rate retrievals from radars. Part II: Results from three wavelength radar-collocated in-situ measurements and CloudSat-GPM-TRMM radar data. J. Appl. Meteor. Climatol., 57, 365-389, https://doi.org/10.1175/JAMC-D-170164.1.

Hitschfeld, W., and J. Bordan, 1954: Errors inherent in the radar measurement of rainfall at attenuating wavelengths. J. Meteor.,
11, 58-67, https://doi.org/10.1175/1520-0469(1954)011\%3C0058: EIITRM\%3E2.0.CO;2.

Hogan, R. J., L. Tian, P. R. A. Brown, C. D. Westbrook, A. J. Heymsfield, and J. D. Eastment, 2012: Radar scattering from ice aggregates using the horizontally aligned oblate spheroid approximation. J. Appl. Meteor. Climatol., 51, 655-671, https:// doi.org/10.1175/JAMC-D-11-074.1.

Hou, A. Y., and Coauthors, 2014: The Global Precipitation Measurement Mission. Bull. Amer. Meteor. Soc., 95, 701-722, https://doi.org/10.1175/BAMS-D-13-00164.1.

Houze, R. A., Jr., and Coauthors, 2017: The Olympic Mountains Experiment (OLYMPEX). Bull. Amer. Meteor. Soc., 98, 2167-2188, https://doi.org/10.1175/BAMS-D-16-0182.1.

Huang, G.-J., V. N. Bringi, A. J. Newman, G. Lee, D. Moisseev, and B. M. Notaroš, 2019: Dual-wavelength radar technique development for snow rate estimation: A case study from GCPEx. Atmos. Meas. Tech., 12, 1409-1427, https://doi.org/ 10.5194/amt-12-1409-2019.

Korolev, A., and G. Isaac, 2003: Roundness and aspect ratio of particles in ice clouds. J. Atmos. Sci., 60, 1795-1808, https://doi.org/10.1175/ 1520-0469(2003)060<1795:RAAROP $>2.0$. CO;2.

— J. W. Strapp, G. A. Isaac, and E. Emery, 2013: Improved airborne hot-wire measurements of ice water content in clouds. J. Atmos. Oceanic Technol., 30, 2121-2131, https://doi.org/ 10.1175/JTECH-D-13-00007.1.

Kuo, K.-S., and Coauthors, 2016: The microwave radiative properties of falling snow derived from nonspherical ice particle models. Part I: An extensive database of simulated pristine crystals and aggregate particles, and their scattering properties. J. Appl. Meteor. Climatol., 55, 691-708, https://doi.org/ 10.1175/JAMC-D-15-0130.1.

Leinonen, J., and Coauthors, 2018: Retrieval of snowflake microphysical properties from multifrequency radar observations. Atmos. Meas. Tech., 11, 5471-5488, https://doi.org/10.5194/ amt-11-5471-2018.

Liao, L., R. Meneghini, T. Iguchi, and A. Detwiler, 2005: Use of dual-wavelength radar for snow parameter estimates. J. Atmos. Oceanic Technol., 22, 1494-1506, https://doi.org/10.1175/ JTECH1808.1.

Liebe, H. J., 1985: An updated model for millimeter wave propagation in moist air. Radio Sci., 20, 1069-1089, https://doi.org/ 10.1029/RS020i005p01069.

McFarquhar, G. M., and Coauthors, 2017: Processing of ice cloud in situ data collected by bulk water, scattering, and imaging probes: fundamentals, uncertainties, and efforts toward consistency. Ice Formation and Evolution in Clouds and Precipitation: Measurement and Modeling Challenges, Meteor. Monogr., No. 58, Amer. Meteor. Soc., https://doi.org/10.1175/ AMSMONOGRAPHS-D-16-0007.1.

Peral, E., and Coauthors, 2019: RainCube: The first ever radar measurements from a CubeSat in space. J. Appl. Remote Sens., 13, 032504, https://doi.org/10.1117/1.JRS.13.032504.

Pianosi, F., K. Beven, J. Freer, J. W. Hall, J. Rougier, D. B. Stephenson, and T. Wagener, 2016: Sensitivity analysis of environmental models: A systematic review with practical workflow. Environ. Modell. Software, 79, 214-232, https:// doi.org/10.1016/j.envsoft.2016.02.008.

Pruppacher, H., and J. Klett, 1996: Microphysics of Clouds and Precipitation. Atmospheric and Oceanographic Sciences Library, Vol 18, Springer Science and Business Media, 954 pp.

Purcell, E. M., and C. R. Pennypacker, 1973: Scattering and absorption of light by nonspherical dielectric grains. Astrophys. J., 186, 705-714, https://doi.org/10.1086/152538. 
Rienecker, M. M., and Coauthors, 2011: MERRA: NASA's Modern-Era Retrospective Analysis for Research and Applications. J. Climate, 24, 3624-3648, https://doi.org/10.1175/JCLI-D-11-00015.1.

Sadowy, G., A. Berkun, W. Chun, E. Im, and S. Durden, 2003: Development of an advanced airborne precipitation radar. Microwave J., 46, 84-98.

Skofronick-Jackson, G., and Coauthors, 2015: Global Precipitation Measurement Cold Season Precipitation Experiment (GCPEX): For measurement's sake, let it snow. Bull. Amer. Meteor. Soc., 96, 1719-1741, https://doi.org/10.1175/BAMS-D-13-00262.1.

Stephens, G. L., and Coauthors, 2008: CloudSat mission: Performance and early science after the first year of operation. J. Geophys. Res. Oceans, 113, D00A18, https://doi.org/10.1029/2008JD009982.

_- and Coauthors, 2012: An update on Earth's energy balance in light of the latest global observations. Nat. Geosci., 5, 691-696, https://doi.org/10.1038/ngeo1580.

Vega, M. A., V. Chandrasekar, J. Carswell, R. M. Beauchamp, M. R. Schwaller, and C. Nguyen, 2014: Salient features of the dual-frequency, dual-polarized, Doppler radar for remote sensing of precipitation. Radio Sci., 49, 1087-1105, https:// doi.org/10.1002/2014RS005529.

von Lerber, A., D. Moisseev, L. F. Bliven, W. Petersen, A.-M. Harri, and V. Chandrasekar, 2017: Microphysical properties of snow and their link to $Z_{e}-S$ relations during BAECC 2014. J. Appl. Meteor. Climatol., 56, 1561-1582, https://doi.org/ 10.1175/JAMC-D-16-0379.1.

Waterman, P. C., 1971: Symmetry, unitarity, and geometry in electromagnetic scattering. Phys. Rev., 3, 825-839, https:// doi.org/10.1103/PhysRevD.3.825.

Weinheimer, A. J., and A. A. Few, 1987: The electrical field alignment of ice particles in thunderstorms. J. Geophys. Res., 92, 14 833-14 844, https://doi.org/10.1029/JD092iD12p14833.

Wood, N. B., T. S. L'Ecuyer, A. J. Heymsfield, and G. L. Stephens, 2015: Microphysical constraints on millimeter-wavelength scattering properties of snow particles. J. Appl. Meteor. Climatol., 54, 909-931, https://doi.org/10.1175/JAMC-D-14-0137.1. 